\title{
Capturing the Interactions Between Ice Sheets, Sea Level and the Solid Earth on a Range of
} Timescales: A new "time window" algorithm

Holly Kyeore Han ${ }^{1}$, Natalya Gomez ${ }^{1}$, Jeannette Xiu Wen Wan ${ }^{1}$

${ }^{1}$ Department of Earth and Planetary Sciences, McGill University, Montreal, H3A 0G4, Canada

5 Correspondence to: Holly Kyeore Han (holly.han@mail.mcgill.ca)

\begin{abstract}
.
Retreat and advance of ice sheets perturb the gravitational field, solid surface and rotation of the Earth, leading to spatially variable sea-level changes over a range of timescales $\left(\sim O 10^{0-6}\right.$ years), which in turn feed back onto ice sheet dynamics. Coupled ice-sheet - sea-level models have been developed to capture the interactive processes between ice sheets, sea level and the solid Earth, but it is computationally challenging to capture short-term interactions $\left(\sim O 10^{0-2}\right.$ years $)$ precisely within longer $\left(\sim O 10^{3-6}\right.$ years) simulations. The classic coupling algorithm assigns a uniform temporal resolution in the sea-level model, causing a quadratic increase in total CPU time with the total number of input ice history steps, which increases with either the length or temporal resolution of the simulation. In this

15 study, we introduce a new "time window" algorithm for sea-level models that enables users to define the temporal resolution at which the ice loading history is captured during different time intervals before the current simulation time. Utilizing the time window, we assign a fine temporal resolution $\left(\sim O 10^{0-2}\right.$ years) for the period of ongoing and recent history of surface ice and ocean loading changes and a coarser temporal resolution ( $\sim 10^{3-6}$ years) for earlier periods in the simulation. This reduces the total CPU time and memory required per model time step while maintaining the precision of the model results. We explore the sensitivity of sea-level model results to the model's temporal resolution and show how this sensitivity feeds back onto ice sheet dynamics in coupled modelling. We apply the new algorithm to simulate the sea-level changes in response to global ice-sheet evolution over two glacial cycles and the rapid collapse of marine sectors of the West Antarctic Ice Sheet in the coming centuries, 25 providing appropriate time window profiles for each of these applications. The time window algorithm improves the total CPU time by $\sim 50 \%$ in each of these examples, and this improvement would increase with longer simulations than considered here. Our algorithm also allows coupling time intervals of annual temporal scale for coupled ice-sheet - sea-level modelling of regions such as the West Antarctic that are characterized by rapid solid Earth response to ice changes due to the thin lithosphere and low mantle viscosities.
\end{abstract}




\section{Introduction}

It is well established that sea-level changes in response to ice-sheet changes feed back onto the evolution of ice sheets (e.g., Gomez et al., 2012; 2015; de Boer et al., 2014; Konrad et al., 2015; Larour et al., 2019).

35 Changes in grounded ice cover perturb the Earth's gravitational field, rotation and viscoelastic solid surface, leading to spatially non-uniform changes in the heights of the sea surface geoid and the solid Earth, i.e., sea-level changes (e.g., Peltier, 1974; Farrell and Clark, 1976; Woodward, 1888; Mitrovica and Milne, 2003). Sea-level changes occur as an instantaneous response to the surface (ice and water) loading changes associated with elastic deformation of the solid Earth and changes in gravity and rotation, followed by a slower response over tens of thousands of years due to the viscous mantle flowing back towards isostatic equilibrium, once again accompanied by gravitational and rotational effects. The spatial and temporal scales of the solid Earth response to ice loading changes depend on the rheological structure of the elastic lithosphere and viscoelastic mantle, which are both radially and laterally heterogeneous (e.g., Dziewonski and Anderson, 1981; Morelli and Danesi, 2004; Nield et al., 2014; An et al., 2015; Lloyd et al., 2020). The contribution from viscous deformation to sea-level changes in regions with thinner lithosphere and lower mantle viscosities such as the West Antarctica occurs on shorter timescales $\left(O \leq 10^{2}\right.$ years; e.g., Barletta et al., 2018) than they do in regions with thicker lithosphere and higher mantle viscosities such as North America (e.g., Mitrovica and Forte, 2004) and is more localized to the loading changes, calling for higher spatiotemporal resolution in modelling applications in these regions.

Spatially variable changes in the sea surface geoid and the solid Earth (i.e., sea level) have different dominant mechanisms in influencing ice sheets in marine and continental settings. The evolution of a marine-based ice sheet is strongly dependent on the slope of bedrock underneath the ice sheet and local ocean depth at the grounding line (e.g., Weertman, 1974; Thomas and Bentley, 1978; Schoof, 2007).

55 Thus, deformation of the bedrock beneath the ice and sea level changes at the grounding line in response to the marine-based ice sheet's growth and retreat affect the ice flux across the grounding line (Gomez et al., 2010, 2012, 2020). In the continental setting, solid Earth deformation beneath an evolving land-based ice sheet alters the slope and elevation of the ice surface in the atmosphere. This, in turn, influences the ice sheet's surface mass balance (e.g., Crucifix et al., 2001; Han et al., 2021; van den Berg et al., 2008). 
The interactions between ice sheets, sea level and the viscoelastic solid Earth are active over a range of timescales, and several studies have developed coupled ice sheet-sea level models to investigate these interactions (Gomez et al., 2012, 2013; deBoer et al., 2014; Konrad et al., 2014). Studies have applied coupled modelling to simulate the evolution of the Antarctic Ice Sheet (AIS) during the last deglaciation (Gomez et al., 2013, 2018, 2020; Pollard et al., 2017), the Pliocene (Pollard et al., 2018) and the future (Gomez et al., 2015; Konrad et al., 2015; Larour et al., 2019), the evolution of the Northern Hemisphere ice sheets over the last glacial cycle (Han et al., 2021) and the global ice sheets over multiple glacial cycles (deBoer et al., 2014). These studies capture the interactions between ice sheets and sea level at a temporal resolution of as short as 50 years for the millennial timescale simulations and 200 years for the glacial timescale simulations, but moving to longer simulations or greater spatiotemporal resolution presents a computational challenge, requiring a trade-off between those two in simulations.

There is a need to overcome this challenge in order to understand ice sheets and sea-level changes over a wider range of timescales and in greater detail, especially as the spatiotemporal resolution and extent of paleo records improves (e. g., Khan et al., 2019; Rovere et al., 2020; Gowan et al., 2021). Motivations include running simulations over longer time periods in the past (e.g., from the warm mid-Pliocene to the modern), or in higher spatiotemporal resolutions in order to accurately capture rapid paleo ice-sheet variability and sea-level rise events observed in geological records (e.g., Ice Rafted Debris events - Weber et al., 2014; Meltwater Pulse 1A event - Fairbanks, 1989; Deschamps et al., 2012; Brendryen et al., 2019).

80 Furthermore, the present-day WAIS sits atop rapidly responding bedrock (e.g., Barletta et al., 2018; Lloyd et al., 2020; Powell et al., 2020) and is under the threat of catastrophic collapse in a warming climate (e.g., SROCC, 2019). To capture the dynamics of such rapid retreat of ice sheets and the associated sea-level changes, models may need to employ annual-decadal scale resolution (e.g., Larour et al., 2019).

85 The computational challenge introduced above arises only in a coupled ice sheet - sea level modelling context where (unlike in stand-alone sea level modelling applications where ice cover changes are prescribed, e.g., Peltier 2004; Lambeck 2014) the ice cover changes are unknown at the start of a 
simulation and predicted by the ice sheet model as the simulation progresses. That is, with the standalone ice age sea-level model algorithm described in Kendall et al. (2005), the model takes in the full history of ice loading at the start of the simulation and computes associated sea-level changes across all time steps and outputs results at once at the end of the simulation. On the other hand, in a coupled icesheet - sea-level simulation, ice cover changes are predicted by a dynamic ice-sheet model and provided to the sea-level model. The sea-level model, in turn, provides updated bedrock elevation and sea surface heights to the ice-sheet model. This exchange of models' outputs happens at every coupling time interval, which necessitates a 'forward modelling' scheme (as described in Gomez et al. 2010) in the sea-level model: The sea-level calculation at every new coupling time interval requires the history of ice loading since the beginning of the coupled simulation as input. The classic forward sea-level modelling algorithm adopted in coupled models employs a uniform temporal resolution throughout a simulation, which leads to a quadratic increase in the amount of surface loading history with the length of a simulation. The sealevel calculation thus becomes more computationally expensive as the simulation progresses and can make very long or very finely temporally resolved simulations computationally infeasible (e.g., Using this framework, coupled simulations in past studies have been limited to 40-125 ky with a temporal resolution of 200 years; Gomez et al., 2013; Han et al., 2021).

105 To overcome this challenge, de Boer et al. (2014) presented what they called a "moving time window" algorithm in a sea-level model (SELEN, Spada and Stocchi, 2007) and performed coupled ice-sheet sea-level model simulations over four glacial cycles (410 ky). Using the characteristics of exponentially decaying viscous deformation of the mantle, de Boer et al. (2014) interpolated "future" viscous deformation associated with ongoing surface loading changes and added up the interpolated values at later time steps to obtain deformation due to "past" loading changes. They also applied a coupling time interval of $1 \mathrm{ky}$, while other studies have suggested that simulations over the last deglaciation require coupling intervals of at least 200 years (Gomez et al., 2013) and coupled simulations of future retreat of the Antarctic ice sheet have adopted coupling times of tens of years or less (Gomez et al., 2015; Pollard et al., 2017; Larour et al., 2019) to capture the decadal to centennial-scale interactions between ice sheets, 115 sea level and the solid Earth. 
In this study, we develop a new time window algorithm, which takes a different approach from deBoer et al. (2014) to overcome the computational challenges posed in coupled ice-sheet - sea-level modelling. We modify the classic forward model sea-level algorithm introduced in Gomez et al. (2010) by systematically reducing the temporal resolution of earlier ice history while maintaining high resolution in recent loading. We present the algorithm in Section 2 and perform a suite of simulations with idealized ice sheet evolution and bedrock geometry to show how the temporal resolution of a sea-level model influences the predicted sea level (Section 3.1) and its influence on Northern Hemispheric Ice Sheet dynamics through the last glacial cycle (Section 3.2). Next, we apply our time window algorithm to simulate sea-level changes due to the evolution of the global ice sheets over the last two glacial cycles and due to future Antarctic Ice Sheet evolution in the coming centuries (Section 3.3), presenting appropriate time window parameters for each scenario. We finish with a discussion of the results and concluding remarks in Section 4.

\section{Methods}

We incorporate our time window algorithm into the forward sea-level model presented in Gomez et al. (2010), which draws on the theory and numerical formulations in Mitrovica and Milne (2003), Kendall et al. (2005), and Mitrovica et al. (2005). In the forward modelling, at every time step $t_{j}$, the sea-level model performs a one-step computation between times $t_{j-1}$ and $t_{j}$ of the global sea-level change associated

135 with ongoing (between $t_{j-1}$ and $t_{j}$ ) and past (between $t_{0}$ and $t_{j-1}$ ) ice loading changes. The numerical form of this is shown in Equation 18 from Gomez et al. (2010):

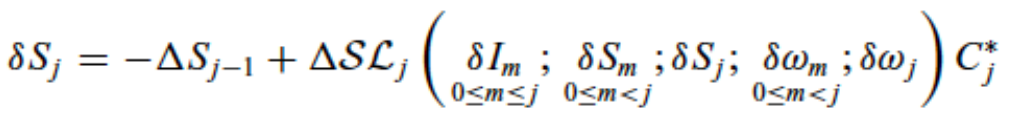

$$
\begin{aligned}
& +\frac{\Delta \Phi_{j}}{g} C_{j}^{*}-T_{0}\left[C_{j}^{*}-C_{0}^{*}\right] \text {, }
\end{aligned}
$$


140 where $j$ is an index for the current time step, $\delta$ represents changes over a single time step (e.g., from $t_{j-1}$ to $t_{j}$ ) and $\Delta$ represents the total change since the initial time $t_{0}$. Thus, $\delta I_{j}$, and $\delta S_{j}$ represent changes in ice thickness $(I)$ and ocean loading $(S)$ between $t_{j-1}$ and $t_{j}$, and $\Delta S_{j}$ represents the change in ocean loading before the current time step between $t_{0}$ and $t_{j-1 .} \Delta \mathcal{S} \mathcal{L}_{j}$ and $\frac{\Delta \Phi_{j}}{g}$ represent the geographically non-uniform and uniform components of the globally defined total sea-level change, respectively. $C^{*}$ represents an ocean-mask function, defined as 1 where sea level is positive and there is no grounded ice, or zero otherwise. $T_{0}$ represents initial topography at $t_{0}$, where the topography is defined as the negative of the globally defined sea level $\left(\Delta S L_{j}=\Delta \mathcal{S} \mathcal{L}_{j}+\frac{\Delta \Phi_{j}}{g}\right)$. Since the focus of this paper is to modify the traditional implementation of the sea-level equation, we refer readers to Mitrovica and Milne (2003), Kendall et al. (2005) and Gomez et al. (2010) for the detailed derivation of this equation and implementation of its numerical algorithm.

Figure 1a represents the classic forward sea-level model algorithm (Gomez et al., 2010) where the time interval $d t$ between each time step of the ice history is uniformly fixed throughout a simulation. By the end of the simulation, the total number of ice history steps $\left(N_{j}\right)$ considered in the calculation across the

155 final time step from $t_{j=f-1}$ to $t_{j=f}$ is simply the length of the simulation $\left(L \_S I M\right)$ divided by the prescribed time interval $(d t)$. Thus, the number of time steps in a simulation increases either by performing a longer simulation (i.e., larger L_SIM) or increasing the temporal resolution (i.e., smaller dt) of a simulation, and the CPU time increases quadratically.

160 Figure $1 \mathrm{~b}$ shows the time window scheme that we develop to save computation time in the sea-level model. This algorithm allows users to assign non-uniform time steps across simulations by dividing the simulations into up to four time intervals. During setup, users define the internal time window lengths $\left(L_{-} I T W_{k}\right)$ and temporal resolutions $\left(d t_{k}\right)$ such that each $L_{-} I T W_{k}$ is divisible by $d t_{k}$ and each $d t_{k}$ is divisible by the finest temporal resolution of the simulation time window ( $d t_{k=1}$, i.e., the coupling time between a dynamic ice-sheet model and the sea-level model). In addition, the sum of all $L_{-} I T W_{k}$ 's must be equal to the total length of a simulation, $L \_S I M$. The algorithm then generates a template mask of binary values to 
resolve the prescribed non-uniform time steps (see Fig. 1b-1). It also creates an array of iceload file numbers that, by convention, start at 0 and increment by 1 each time step forward. When the simulation begins (i.e., takes one step forward from $j=0$ to $j=1$ ), the first two elements of this array (iceload files ' 0 ' and ' 1 ') overlap the last two elements of the binary template (see the top red box in 1b-2). Overlapping elements are multiplied together to generate masked iceload history files for the sea-level model to read in at the time step. The sea-level model only reads in those ice files masked with binary value of 1. However, to ensure that the solid Earth retains the memory of the initial loading, the sea-level model always reads the initial iceload file (see the dotted box and resulting masked iceload files in Fig. 1b-2).

At every simulation step $\mathrm{j}>1$, the template marches forward by one element relative to the iceload file array, and the multiplication process repeats followed by the sea-level calculation. Our algorithm starts filling in the first internal time window to its prescribed length $\left(L_{-} I T W_{1}\right)$, followed by the other internal windows in order $\left(L_{-} I T W_{k}\right.$ for $\left.\mathrm{k}=2,3,4\right)$. By the end of the simulation, the time window grows to the full prescribed profile (see the $j=8$ result in Fig. 1b-2).

Overall, this time window algorithm limits the increase in the amount of surface loading history with simulation length or temporal resolution, improving the computational efficiency of sea-level model calculations (compare $N_{j}$ values in Fig. 1a and Fig. 1b-2). The time window algorithm also enables the sea-level model to capture both short- and long-term interactions between ice sheets, sea level and the solid Earth in coupled ice-sheet - sea-level simulations.

In the next section, we perform a suite of sensitivity tests performing standalone sea-level simulations and coupled ice-sheet - sea-level simulations to test the sensitivity of model results to temporal resolution of the sea-level model. The sea-level model takes two inputs, an Earth model and an ice history model. We adopt 1-D Earth model in all simulations; the elastic and density profile of the Earth structure are given by the seismic model PREM (Dziewonski \& Anderson, 1981). For mantle viscosity, we adopt a lithospheric thickness of $120 \mathrm{~km}$ and upper mantle viscosity of $5 \times 10^{20} \mathrm{PaS}$ and lower mantle viscosity of $5 \times 10^{21} \mathrm{PaS}$ in sections 3.1-3.3.1. For section 3.3.2 in which we perform simulations over Antarctica, we 
195 adopt the best-fitting radially varying Earth model from Barletta et al. (2018), characterized by a lithospheric thickness of $60 \mathrm{~km}$ and upper mantle viscosities of $\sim 10^{18}-10^{19} \mathrm{PaS}$. Ice history inputs are described in each section with reference to corresponding figures. In all simulations, we perform sea-level calculations up to spherical harmonics degree and order of 512.

\section{Results}

\subsection{Sensitivity of sea-level model outputs to temporal resolution}

Before exploring the new time window algorithm in sections 3.2 and 3.3, we begin by performing a series of experiments with a standalone sea-level model adopting the classic algorithm to demonstrate how predicted topography changes (that is, negative of sea-level changes) at near and far-field locations vary with the (uniform) temporal resolution of the ice history (as in Fig. 1a). We generate an idealized axissymmetric input ice history based on the equation for an equilibrium ice surface profile for viscous ice provided in Cuffey and Paterson (1969, The Physics of Glacier), and the ice sheet grows and retreats centered at the South pole (Fig. 2). The initial topography for the buildup-phase simulations is idealized such that its elevation is $1000 \mathrm{~m}$ between latitude $60-90 \mathrm{~S}$ degrees and $-1000 \mathrm{~m}$ (ocean with a depth of $1000 \mathrm{~m}$ ) everywhere else. In Fig. 2, we consider predicted changes in topography at three locations: A location at the center of loading (latitude $90 \mathrm{~S}$ degrees), near the periphery of the ice sheet at its maximum extent (latitude 65S degrees, where the peripheral bulge formed around the ice sheet is largest), and in the

215 far-field near the equator at latitude 0 degrees. We begin by discussing the general behaviour of topography at these sites in benchmark simulations performed at a temporal resolution of 1 ky (shown by the black dots in Fig. 2).

Figures 2a-c show results from buildup-phase simulations. The ice sheet thickness and extent grow over

$20 \mathrm{ky}$ at a uniform rate at the centre and the edge of the loading, to the thickness of $3500 \mathrm{~m}$ (top panel of Fig. 2a) and the extent reaching latitude $65 \mathrm{~S}$. In response, the topography subsides at the centre of loading (middle panel of Fig. 2a) and uplifts at the peripheral point (middle panel of Fig. 2b). Far-field equatorial 
sites experience a decrease in sea level (increase in topography) as ice becomes locked up on land (middle panel of Fig. 2c).

Figures 2 d-f show results over a 20 -ky long retreat phase. The initial topography for these simulations is adopted from the final topography modelled in the benchmark buildup-phase simulation with $d t=1 \mathrm{ky}$ (i. e., black dots in the middle panel of Fig. 2a). As the ice sheet retreats, the topography uplifts at the center of the ice load (middle panel of Fig. 2d), subsides at locations peripheral to the ice (middle panel Fig. 2e) and the far-field regions experience sea-level rise (middle panel of Fig. 2f).

Next, we compare simulations performed at lower temporal resolutions of $5 \mathrm{ky}, 10 \mathrm{ky}$ and $20 \mathrm{ky}$ to our benchmark simulations at 1 ky resolution. Though all of the simulations capture the main characteristics of deformation at each location, the magnitude of the deformation during both the ice-sheet buildup and retreat phases at all three locations decreases with decreasing temporal resolution (i.e., higher dt). For example, when comparing the 5 ky-resolution simulation to the benchmark simulation for the buildup phase (red line in the bottom panel of Fig. 2a), the subsidence beneath the ice during ice growth is reduced by up to $51.7 \mathrm{~m}$. Likewise, the simulations with 10-ky and 20 ky-resolution (blue and pink lines) underestimate the subsidence by up to $173 \mathrm{~m}$ and $349 \mathrm{~m}$, respectively. The underestimation is due to the timing of the applied load in each simulation; as shown by the step function ice loading increases in the top panels of Fig. 2a and d, simulations with coarser temporal resolution have delayed increases in ice loading. For example, the loading change for the first $10 \mathrm{ky}$ and the $5 \mathrm{ky}$ resolution simulation is applied in two steps at 5 and $10 \mathrm{ky}$, while in the $10 \mathrm{ky}$ resolution simulation, the full load is applied once at 10 ky. The latter thus does not capture the viscous signal due to the loading that takes place before $10 \mathrm{ky}$.

245 These maximum differences ("errors") and the spread of the errors decrease gradually towards zero with time. For these simulations, the errors in total topography change become less than $1 \%$ of the total subsidence $(801 \mathrm{~m})$ in the benchmark simulation by $60 \mathrm{ky}$ (i.e., within $40 \mathrm{ky}$ after the completion of loading/unloading event at $20 \mathrm{ky}$ ). 
Note that at the equatorial site, the rate at which the error decreases towards zero is slower than the nearfield sites (e.g., see the pink line after reaching its peak in Figs. 2c and f). This is because there is active water loading occurring at this site even after the ice has stopped evolving, which prolongs the differences in deformation of the lower resolution simulations compared to the benchmark simulation ("water-loading effects", e.g., Han et al., 2018).

The timing of the maximum errors at each site corresponds to the size of topography changes at the site, which in turn depends on the distance to, and size of an evolving ice sheet. For example, at the near-field sites during the buildup phase, the peak differences in simulations occur as soon as the ice starts loading at the centre-of-loading site (bottom panel of Fig. 2a) while at the peripheral-bulge site the peak differences occur at $20 \mathrm{ky}$ when the ice sheet reaches its maximum volume and extent (bottom panel of Fig. 2b). During the retreat phase, the peak differences at the peripheral-bulge site occur as soon as the ice starts retreating. The differences then get smaller at this site as the ice sheet and its peripheral bulge retreat further away from the site towards the pole (bottom panel of Fig. 2e). The ice sheet's centre, on the other hand, experiences the peak differences at $20 \mathrm{ky}$ when ice loading directly above this site disappears (bottom panel of Fig. 2d).

While the timing of the maximum differences in the near-field sites is most sensitive to the size and proximity of ice to the sites, at the equatorial site it is the most sensitive to the ice volume change. During the buildup phase, the greatest sea-level changes at the equatorial site (and thus the maximum errors) occur at $20 \mathrm{ky}$ (bottom panel of Fig. 2c). During the retreat phase, the errors peak as soon as the ice starts retreating and the rate of change of ice volume is largest (bottom panel of Fig. 2f). For both phases, the timing of maximum error is related to the maximum ice volume change. We note that the ice thickness at the centre of loading (as shown in the top panels of Fig. 2a and d) changes linearly, but the actual volume change is nonlinear because of the changes in the ice sheet's extent; the volume change across one time step is greater when the ice sheet is more extensive. 
Overall, the idealized-loading simulations show that sea-level model outputs are sensitive to the model temporal resolution. This is because the timing of ice loading is different with different temporal resolutions. The sensitivity at a location depends on its setting (above or below sea level), the size of ice loading changes and the distance (near-field or far-field) to the changing ice load. However, the sensitivity at all sites decreases with time after the ice loading event. These results suggest (as expected from the literature on the viscoelastic response of the Earth to surface loading, e.g., Peltier, 1974) that higher resolution information about ice cover changes is required for the ice history immediately prior to the current time step in a simulation, and lower resolution will suffice for earlier ice cover changes. The

285 specific temporal resolution required will depend on both the rates of change of the ice cover and the Earth's viscosity structure, which we explore in two contrasting examples in Section 3.3.

In this section, we have highlighted the sensitivity of predicted sea-level changes to the temporal resolution of the inputted ice history in classic, standalone sea-level simulations. In the following section, we explore how the differences in sea level predicted with different temporal resolution influence the ice sheet evolution in coupled ice sheet - sea level simulations and how the time window algorithm can reconcile the errors.

\subsection{Sensitivity of modelled ice sheet dynamics to temporal resolution with a coupled sea-level model}

This section explores how the differences in predicted sea-level change due to temporal resolution of the input ice history discussed in the previous section impact ice dynamics in coupled ice-sheet-sea-level model simulations. To do this, we perform a suite of coupled simulations over the Northern Hemisphere through the last glacial cycle (125 ky) incorporating different sizes of uniform time steps with the standard algorithm (Fig. 3a) and nonuniform time steps applying the time window algorithm (Fig. 3b). We employ the PSU 3D dynamic ice-sheet model by Pollard and DeConto (2012) and adopt the same set of ice model parameters (e.g., climate forcing, basal slipperiness, spatial and temporal domain and resolutions) used in the simulations from the main text of Han et al. (2021). The ice-sheet model has a standalone time step of $0.5 \mathrm{yr}$. We note that the coupling interval over which the ice-sheet model and sea-level model exchange 
their outputs (i.e., ice thickness and topography, respectively) corresponds to the size of the most recent time step within the sea-level model (i.e., $d t_{1}$ in Fig. 1b).

Figure 3a demonstrates that the simulations with a higher temporal resolution (i.e., smaller ' $d t$ ' in the sealevel model and thus more frequent exchange of outputs between the ice-sheet model and the sea-level model) yield a higher volume of modelled NHIS during the time between $\sim 80-20 \mathrm{ka}$. Differences in ice volume between the simulations start diverging around $80 \mathrm{ka}$ and persist until the Last Glacial Maximum $(20 \mathrm{ka})$ in the model time. The difference in sea-level-equivalent ice volume is up to $11.6 \mathrm{~m}$ between the simulations with time intervals of $d t=0.1 \mathrm{ky}$ and $d t=1 \mathrm{ky}$ at $80 \mathrm{ka}$ (compare black dotted line and blue line in Fig. 3a). Spatially, the differences occur mainly in the Laurentide Ice Sheet in North America (we don't show this in the figure). As illustrated in Fig. 2, a lower temporal resolution of the ice history during the Laurentide Ice Sheet retreat before $80 \mathrm{ka}$ leads to less uplift of the bedrock beneath the ice sheet, keeping the ice surface at a lower (and thus warmer) evelation in the atmosphere. This lower ice elevation causes more intense deglaciation of the Laurentide Ice Sheet. It also prohibits the ice sheet from growing large during buildup phases later on (the role of deformational effects on ice sheet dynamics is discussed in detail in Han et al. 2021). Furthermore, The NHIS volume fluctuation becomes less smooth when the coupling time interval is increased to $\mathrm{dt}=5 \mathrm{ky}$ and $\mathrm{dt}=10 \mathrm{ky}$ (red and grey lines in Fig. 3a). We presume that this is because a large change in bedrock over a long coupling time causes the ice-sheet model to respond unstably. These results suggest that Northern Hemisphere coupled simulations over the last glacial cycle require a coupling time of hundreds of years or less to accurately capture the interactions between the ice sheets, bedrock elevation and sea level (compare the black-dotted, black and blue lines in Fig. 3a).

While we might expect that the compute time would always increase with higher temporal resolution in the case of uniform time stepping (Fig. 1a), it is interesting to note that the 10-ky time-step simulation took an hour longer than the 5-ky case. This is because in the former simulation, the ice model took longer to converge to a solution because of infrequent and dramatic bedrock changes provided by the sea-level model (as hinted by the unstable fluctuation in the ice volume - the grey line in Fig. 3a). Finally, while 
there are very small differences in predicted ice volume between the $\mathrm{dt}=0.2 \mathrm{ky}$ and $\mathrm{dt}=0.1 \mathrm{ky}$ simulations (black and black- dotted lines in Fig. 3a), CPU time increases by greater than a factor of two from $\sim 45$ to $\sim 98 \mathrm{hr}$, suggesting that $\mathrm{dt}=0.2 \mathrm{ky}$ is a suitable choice of coupling time for glacial cycle simulations.

In Fig. 3b, we apply the time window algorithm to the coupled glacial-cycle simulation rather than adopting uniform temporal resolution in the ice history. We perform three simulations with different time window profiles illustrated in the schematics shown in Fig. 3c. All simulations incorporating the time window predict the ice volume changes of the standard simulation with the uniform time stepping of 0.2 ky well (see the magenta lines and the black line overlapping in Fig. 3b), and the CPU time is reduced by $\sim 12-14 \mathrm{hr}$ (Fig. 3d). In the standard simulation, the number of ice history files that the sea-level model needs to read in at a given time step increases linearly with time (black line in Fig. 3d). In contrast, with the time window algorithm, it increases linearly initially within the first internal time window $\left(L_{-} I T W_{l}=\right.$ $5 \mathrm{ky}$ ), and then nearly capped, increasing by one intermittently when transitioning from one internal time step to the next. (e.g., in Figs. 5c, g and k, coloured lines nearly flatten). The number of files is capped at 145 files in time window profile 1, at 97 files in profile 2, and at 73 files in time window profile 3 . In all cases, the time window algorithm allows for faster computation while maintaining precision (Figs. $3 \mathrm{~b}$ and d).

In this section, taking the last glacial cycle as an example, we have shown that a coarse temporal resolution (e.g., $\mathrm{dt}=1 \mathrm{ky}$ or longer) causes less precise coupled ice-sheet - sea-level simulation results. We have also demonstrated that how the time window algorithm can be used in coupled simulations to maintain the precision of the modelled topography changes and ice sheet dynamics while significantly reducing the computational cost compared to simulations with the standard algorithm. In the same way, the time window algorithm can be applied to other coupled simulations that are otherwise infeasible. In the next section, we derive time window profiles that are suitable for two-glacial-cycle global ice-sheet simulations and the future rapidly retreating Antarctic Ice Sheet simulations. 


\subsection{Derivation of time window profiles for different applications}

In this section, we apply the time window algorithm in the sea-level model to two contrasting examples. First, we consider sea-level changes in response to the evolution of global ice sheets over the last two glacial cycles (240 ky) modified from Han et al. (2021). Then, we consider a simulation of the rapid future retreat of the West Antarctic Ice Sheet in the coming centuries taken from DeConto et al. (2021). West Antarctica is known to have an upper mantle viscosity up to several orders of magnitude lower than on average (Barletta et al., 2018; Lloyd et al., 2020; Nield et al., 2014). For each scenario, we perform a suite of simulations in which we vary the time window parameters (i.e., $L_{-} I T W_{k}$ and $d t_{k}$; Fig. 1) and compare them to a benchmark simulation with uniform high-resolution time stepping to arrive at an optimal choice of a time window profile. Here we note that the experiments are done in standalone sea-level simulations (i.e., ice cover is prescribed rather than provided by a dynamic ice-sheet model) because the benchmark coupled simulations for these scenarios become less feasible without the time window algorithm.

\subsubsection{Application to global ice cover changes over the last two-glacial cycles}

Figures 4a-c show ice volume changes over the last $240 \mathrm{ky}$ and snapshots of the maximum and minimum extent of global ice cover predicted from a coupled ice sheet - sea-level model simulation in Han et al. (2021) that we adopt here as an input to the sea-level model. The original simulation covers the last glacial cycle (125 ka). It includes ice-cover changes predicted with the dynamic PSU ice-sheet model (Pollard \& DeConto, 2012) in the Northern Hemisphere and Antarctic ice cover changes taken from the ICE-6G_C ice history model (Argus et al., 2014; Peltier et al., 2015). To extend our ice history input to cover two 385 glacial cycles, we first take the ice history for $120 \mathrm{ka}$ from the original simulation (Han et al. 2021), then repeat this ice history to cover an additional glacial cycle going back to $240 \mathrm{ka}$. We replace the ice history between 125-120 ka with the ice history between 120-115 ka. This is to make the ice volume curve continuous at the last interglacial. We note that the goal of this experiment is not to produce an accurate 
glacial history but to produce a sample long timescale, global ice history that contains the spatiotemporal detail provided by a dynamic ice-sheet model.

To explore the choice of time window parameters for this global glacial-cycle scenario, we first perform a standard sea-level simulation in which we assign a uniform temporal resolution of 0.2 ky throughout the 240 ky simulation. We take this simulation as our benchmark, and then perform a suite of simulations in which we systematically vary the temporal resolution (dt) of internal time windows (ITW) that cover periods 240-120 ka, 120-50 ka and 50-20 ka in the simulation (see the internal time windows marked by dashed lines in Fig. 4a). We choose these internal time windows based on the timing of ice volume variations and the results of our idealized tests in section 3.1. That is, our first internal time window covers the last deglaciation, the next covers the preceding growth phase in the simulation, then the rest of the glacial cycle back to the last interglacial, and finally the entire previous glacial cycle. We note that in the absence of knowing the specific details of the ice cover changes a priori (as in coupled model simulations), the internal time windows may also be set based on the timing of the climate forcing that serves as input to the model. Sensitivity tests (not shown here) varying the internal time windows lengths to account for potential offsets between the timing of climate forcing and ice sheet response indicate that the timing of these internal time windows need not be set very precisely, with less sensitivity for earlier ice history.

When we explore each internal time window in turn by varying the internal time step (i.e., temporal resolution $d t$ ), starting from the earliest, and fixing the temporal resolution at $0.2 \mathrm{ky}$ for all periods beyond the internal time window. Then, we compare the total CPU time (Fig. 5d) and the precision of our results by calculating the root mean squared errors (RMSE) in predicted topography from these simulations to results from the benchmark simulation. The RMSE are calculated based on the following expression:

$$
\operatorname{RMSE}\left(t_{j}\right)=\sqrt{\frac{1}{N} \sum_{l}^{L=512} \sum_{m}^{M=1024}\left[T\left(t_{j}, l, m\right)_{s t d}-T\left(t_{j}, l, m\right)_{t w}\right]^{2}}
$$


415 Where $j$ represents the time index, $N$ represents the number of grid points (in our case, 512 times 1024 for the Gauss-Legendre sea-level model grid), $T\left(t_{j}, l, m\right)_{s t d}$ and $T\left(t_{j}, l, m\right)_{t w}$ represent predicted topography at time $t_{j}$ from the standard simulation and the time window simulation.

Once we choose an optimal temporal resolution for the internal time window based on the calculated RMSE and CPU time, we move on to explore the next internal time window and we repeat the same procedure.

We start by exploring the internal time window covering the earliest period between 240-120 ka (see the purple bar in Fig. 5a). Varying the internal time step between 5-40 ky for this period (Figs. 5a-d), the RMSE in predicted topography is zero for the first $120 \mathrm{ky}$ (Fig. 5b) because the time window profile matches the $0.2 \mathrm{ky}$ ice history time-stepping in the benchmark simulation (as shown in the black bar indicating 120-0 ka in Fig. 5a). RMSE then starts increasing for all simulations once the simulations proceed past $120 \mathrm{ka}$. The simulations with an internal time step of $20 \mathrm{ky}$ and $40 \mathrm{ky}$ show noticeably greater RMSE than the simulations with a smaller internal time step of $5 \mathrm{ky}$ and $10 \mathrm{ky}$, both of which have RMSE below $0.2 \mathrm{~m}$ throughout the last glacial cycle except at $5 \mathrm{ka}$ when it rises to $0.35 \mathrm{~m}$. The fluctuations in the RMSE curves are mainly associated with the sea-level model not capturing the highs and lows in the input ice history. Taking the simulation with the internal time step of $\mathrm{dt}=40 \mathrm{ky}$ (blue line in Fig. 5b) as an example, the RMSE peaks at around $40 \mathrm{ka}$ because the sea-level model only captures snapshots of ice at their local minimum (at $240 \mathrm{ka}, 200 \mathrm{ka}$ and $160 \mathrm{ka}$ ), missing multiple glacial peaks at $230 \mathrm{ka}, 210 \mathrm{ka}$ and $190 \mathrm{ka}$ within those periods (Fig. 4a).

Figures $5 \mathrm{c}$ and $\mathrm{d}$ show the total number of ice history steps considered and the cumulative CPU time it has taken for the sea-level model to perform calculations at time step $t_{j}$ in the standard simulation (grey line) and all other simulations that incorporate the time window parameters (non-grey lines). The standard simulation increases linearly in total number of ice history steps up to 1200 and quadratically in CPU time, and the entire 240-ky long simulation takes $\sim 58.4 \mathrm{hr}$. The total number of ice history steps starts flattening for the simulations with shorter time step (coloured lines) $120 \mathrm{ka}$, resulting in the reduction in 
the CPU time to $~ 46.8-50.3 \mathrm{hr}$. We note that the CPU time starts diverging earlier that $120 \mathrm{ka}$, and this is because measured CPU times may fluctuate in between 10-17\% even with the same CPU (We perform the calculations on Intel Gold 6148 Skylake@ $2.4 \mathrm{GHz}$ nodes provided by Compute Canada Beluga cluster). Based on these results, we choose an internal time step of $10 \mathrm{ky}$ for the first internal time window (240-120 ka) and proceed to explore the internal time steps for the next internal time window between 120-50 ka.

450 Figures $5 \mathrm{e}-\mathrm{h}$ show the results of simulations in which we vary the internal time step for the period between $120-50 \mathrm{ka}$ (purple bar in Fig. 5e) while fixing the first period from 240-120 ka to $d t=10 \mathrm{ky}$. Here we see that the simulation with temporal resolution of $1 \mathrm{ky}$ (red line in Figs. 5f-h) has comparable RMSEs to the RMSEs in the simulation with temporal resolution of $0.2 \mathrm{ky}$ for this internal time window (black line in Figs. 5f-h) with comparably low computing time to the other lower temporal resolution simulations (pink and blue lines in Figs. 5f-h). The total CPU time is reduced to $29.7 \mathrm{hr}$ in this case, a $49 \%$ reduction compared to the benchmark simulation for this internal time window (compare red and grey line in Fig. 5h). Hence, we adopt a temporal resolution of $1 \mathrm{ky}$ for this period.

Finally, Figs. 5i-1 explores the effects of varying the size of the internal time step for the period between 50-20 ka (purple bar in Fig. 5i). Based on the above discussion, the size of the internal time steps for the periods 240-120 ka and 120-50 ka are fixed at $d t=10 \mathrm{ky}$ and $1 \mathrm{ky}$, respectively. We arrive at the final optimal time window profile by identifying $d t=0.4 \mathrm{ky}$ (red line in $5 \mathrm{~h}-\mathrm{i}$ ) as an optimal internal time step for this internal time window. This profile keeps the RMSEs in output topography below $0.4 \mathrm{~m}$ throughout the entire simulations. The total CPU time is reduced to $\sim 26.9 \mathrm{hr}$, a $54 \%$ reduction compared to the benchmark with uniform time stepping of $0.2 \mathrm{ky}$. We note that the CPU times shown in Fig. 5 are based on standalone sea-level simulations only. This time window algorithm is designed for sea-level calculations performed within a coupled ice sheet - sea level simulation, and compute times will be similarly reduced in this context. Moreover, the reduction will grow for longer simulations as the CPU time in the standard simulation will increase quadratically whereas the time window simulation will suppress the rapid growth of rate of increase. 


\subsubsection{Application to future Antarctic Ice Sheet changes}

In this section, we develop a time window profile for application to simulating future West Antarctic Ice Sheet (WAIS) collapse based on the same methodology that we use for the global glacial-cycle scenario in the previous subsection. We adopt a simulation of future AIS evolution from DeConto et al. (2021) in which marine sectors of the WAIS collapse over hundreds of years is driven by RCP8.5 climate warming scenario (ref climate warming) and marine ice sheet instability. The simulation does not include ice shelf hydrofracture and ice cliff instability (Pollard et al., 2015) and the East Antarctic Ice Sheet remains intact during the simulation. The rapid retreat of the WAIS and the weak solid Earth structure together suggest that interactions between ice sheets, sea level, and the solid Earth in the coupled ice-sheet - sea-level model simulations may need to be captured at decadal timescales or less. We therefore perform our benchmark sea-level simulation for this scenario with a uniform (standard) temporal resolution of $\mathrm{dt}=1$ yr. We also perform additional standard simulations with a coarser temporal resolution of $\mathrm{dt}=5 \mathrm{yr}, 10 \mathrm{yr}$ and $50 \mathrm{yr}$ for comparison. We then perform a suite of simulations in which we vary the temporal resolution between $\mathrm{dt}=5-50 \mathrm{yr}$ within the four internal time windows shown in Fig. 6a (also see the purple bars in Figs. 7a, e and i).

490 Fig. 6 shows AIS volume changes and maps of the AIS thickness at the beginning and end of the 550-yr simulation beginning in $1950 \mathrm{CE}$ from Deconto et al. (2021) along with total sea-level change in Antarctica across the simulation predicted from our benchmark standalone sea-level simulation. Marinegrounded ice sheets in the Amundsen Sea Embayment in West Antarctica retreats completely along with the Ross and Ronne-Flinchner Ice Shelves (Figs. 6b-c) and strong sea-level fall occurs in the region 495 (shown in dark orange in Fig. 6d). Accordingly, in these marine sectors, it becomes important to capture deformation at the grounding line accurately within coupled model simulations. In the remainder of this section, we first select a time window profile based on global RMSE in Fig. 7 and then we test the performance of the chosen time window at capturing deformation at the grounding line in Fig. 8. 
We start by finding an optimal internal time step (i.e., temporal resolution) for the period between 0-200 yr simulation time (Fig. 6a; also marked as a purple bar in Fig. 7a) during which the WAIS starts retreating, and the rate of retreat starts accelerating just after $100 \mathrm{yr}$. Fig. 7b shows that RMSEs in predicted topography compared to the benchmark simulation start increasing after $350 \mathrm{yr}$ (this is because the temporal resolution is set to be the same as that in the benchmark simulation during the first $350 \mathrm{yr}$ ). The RMSEs remain smaller than $10 \mathrm{~cm}$ for simulations with an internal time step of $10 \mathrm{yr}$ and $25 \mathrm{yr}$ (red and magenta lines in Fig. 7b) and below $0.85 \mathrm{~cm}$ with an internal time step of $5 \mathrm{yr}$ (black line in Fig. 7b). The number of ice history steps $\left(N_{j}\right)$ that the sea-level model considers at time step $t_{j}$ starts diverging after $350 \mathrm{yr}$. At the last time step of the simulation, the benchmark simulation considers 550 ice history steps while $N_{j}$ considered for the simulations with an internal time step $\mathrm{dt}=5-50 \mathrm{yr}$ are reduced by $\sim 29-36 \%$, 510 respectively (Fig. 7c). The total CPU times are reduced by $\sim 4-8 \%$, from $\sim 17 \mathrm{hr}$ with the standard simulation to between $\sim 15.6-16.3 \mathrm{hr}$ for the others (Fig. $7 \mathrm{~d}$ ). We choose $\mathrm{dt}=5 \mathrm{yr}$ as an appropriate internal time step for the period between 0-200 yr (the black lines in Figs. 7b-d), which minimizes the RMSE with comparable CPU time to the other simulations.

515 Next, we explore the period 200-350 yr (Figs. 7e-h) during which the most intense ice loss occurs (Fig. 6a). The simulations with internal time step of $25 \mathrm{yr}$ and $50 \mathrm{yr}$ show a noticeable increase in RMSEs compare to those with a smaller internal time step (compare the blue and magenta lines to red and black lines in Fig. 7f). Comparing the simulations with a finer resolution of $\mathrm{dt}=5 \mathrm{yr}$ (black line) and coarser resolution of $\mathrm{dt}=50 \mathrm{yr}$ (blue line), the former considers the total of 270 ice history steps and the compute time is $\sim 11.5 \mathrm{hr}$, which is 27 more ice history steps and $\sim 2 \mathrm{hr}$ longer compute time than the latter simulation. Since the simulation with the fine internal time step of $5 \mathrm{yr}$ is entirely feasible, and the RMSE in predicted topography is minimal below $0.04 \mathrm{~m}$, we choose $\mathrm{dt}=5 \mathrm{yr}$ (black lines in Figs. $7 \mathrm{f}$-h) as our temporal resolution for this period.

525 Finally, Figs. 7i-1 show the results of exploring the temporal resolution for the period between 350-450 yr. Again, the simulation with the internal time step of $5 \mathrm{yr}$ outperforms the other simulations that have a 
coarser temporal resolution, keeping the RMSEs in predicted topography below $0.07 \mathrm{~m}$ throughout the simulation (black line in Fig. 7j), without a significant increase in compute time and ice history steps compared to the other coarser simulations (Fig. 7k). The total computing time for the $5 \mathrm{yr}$ simulation is

$5308.5 \mathrm{hr}$ (Fig. 71), which is a $\sim 50 \%$ reduction from the computing time of the benchmark simulation $(\sim 17$ $\mathrm{hr}$ ) and only $\sim 3-6 \%$ longer than the other simulations $(\mathrm{dt}=10 \mathrm{yr}, 25 \mathrm{yr}$ and $50 \mathrm{yr})$. Thus, we arrive at an ideal time window profile (black line shown in Figs. 7j-1).

Having chosen the time window profile for the future AIS retreat scenario, we compare predicted topography from this time window simulation to that from the standard simulations that incorporate coarser uniform temporal resolution of $5 \mathrm{yr}, 10 \mathrm{yr}$ and $50 \mathrm{yr}$. Figure 8 shows the snapshots ice thickness and predicted topography at model times $250 \mathrm{yr}, 350 \mathrm{yr}$ and $550 \mathrm{yr}$ relative to $0 \mathrm{yr}$ along a cross-section in Amundsen Sea Embayment across which the grounding line retreats during the simulations (shown by the red line in Fig. 6d). Figures 8a-c indicate a rapid retreat of the marine-based West Antarctic Ice Sheet on a reverse-sloped bed between 250-550 yr and substantial bedrock uplift in response to the ice unloading. When the ice-sheet retreat and associated topography changes are small in the first 250 years of the simulation (see the solid blue and dotted blue lines in Fig. 8c), the differences in predicted global topography from standard simulations with resolutions of 5- 50 years (blue, red and magenta lines) compared to the benchmark $1 \mathrm{yr}$ simulation reach up to $10 \mathrm{~m}$. The spread of the differences increases even more as the retreat becomes more intense after $250 \mathrm{yr}$ (see the changes in RMSE from Fig. 8d to e). By $350 \mathrm{yr}$, after $\sim 330 \mathrm{~km}$ of grounding line retreat along the cross section (solid blue to dashed blue lines in Fig. 8b), the standard simulation that incorporates $\mathrm{dt}=50 \mathrm{yr}$ shows up to $80 \mathrm{~m}$ of difference in predicted topography compared to the benchmark simulation. The standard simulation that incorporates a relatively fine resolution of $5 \mathrm{yr}$ still shows topographic differences in the grounding zone reaching a maximum of $5 \mathrm{~m}$ during the simulation (red line in Fig. 8e). Meanwhile the maximum difference in topography in the grounding zone in the simulation adopting the time window algorithm is less than $0.1 \mathrm{~m}$ by $350 \mathrm{yr}$ and less than $1 \mathrm{~m}$ by $550 \mathrm{yr}$, or $0.24 \%$ of the total deformation (up to $391 \mathrm{~m}$ by the end of the simulation). 


\section{Discussion and Conclusions}

We have developed a new time window algorithm that assigns nonuniform temporal resolution to the inputted ice cover changes in a forward sea-level model (Gomez et al., 2013, and restricts the linear increase in the number of ice history steps that a sea-level model has to consider at each time step. Our algorithm allows coupled ice-sheet-sea level models to capture short-term $O\left(\leq 10^{2} \mathrm{yr}\right)$ interactions between ice sheets, the solid Earth and sea level within simulations across a range of timescales. The algorithm improves computational feasibility while maintaining the precision of the sea-level (and thus coupled ice-sheet - sea-level) simulations.

In benchmarking the algorithm, we first tested the sensitivity of sea-level model outputs (i.e., predicted topography) to the temporal resolution adopted in idealized simulations (Fig. 2). Our results show that sea-level simulations with coarser temporal resolution do not accurately capture the timing and geometry of ice loading, and this leads to missing viscous signals and thus an underestimation of topography changes. We also found (as suggested in earlier literature, e. g., Peltier, 1974) that there is a stronger sensitivity to more recent loading, indicating that higher temporal resolution is required close to the current time step in a simulation. We then performed coupled ice-sheet - sea-level simulations through the last glacial cycle over the Northern Hemisphere with varying temporal resolution. Our results demonstrated that the underestimated magnitudes in predicted topography and infrequent topography updates in the coupled simulation with a lower-temporal resolution lead to smaller and sometimes unstable ice volume fluctuations (Fig. 3a). Our results also identify that $0.2 \mathrm{ky}$ is the optimal coupling time interval for glacial-cycle simulations with broad spatial scale on a model of Earth structure representative of the global average Earth structure typically adopted in ice-age sea-level studies (e.g., 575 Lambeck et al., 2014). When we utilize the time window algorithm and capture short-term, recent interactions while assigning coarser temporal resolution beyond the most recent 5 ky during the simulation, the NHIS dynamics through the last glacial cycle are captured well while saving the compute time by $\sim 26-31 \%$ (Figs. 3b-d). 
After benchmarking the time window algorithm, we explored suitable time window parameters that improve computational efficiency while maintaining the precision of model outputs for two different sealevel model applications: A simulation of global ice-sheet evolution through two glacial cycles (Figs. 4 and 5); and a centennial-timescale future WAIS retreat scenario with an adopted Earth structure characteristic of the region with a thin lithosphere and low mantle viscosities (Figs. 6-8). The sample time window parameters we provide improve computational efficiency by $\sim 54 \%$ and $\sim 50 \%$ for each application, respectively, and the improvement would grow for longer simulations.

Overall, our results demonstrate that capturing short-term responses during a period including and temporally close to ongoing surface loading changes is important. At the same time, a coarser temporal resolution can be used for past loading changes. This is expected based on normal mode theory where the solid Earth signals comprised of normal modes with shorter decay times associated with the loading changes would have already relaxed out after simulations have proceeded (Peltier, 1974).

Previously, de Boer et al. (2014) developed what they call a "moving time window" algorithm in their coupled ice-sheet - sea-level model, which they applied to global ice sheets over four glacial cycles (410 ky). They utilized the characteristics of exponentially decaying viscous deformation and the linearity of 1-D Maxwell viscoelastic rheology and interpolated "future" bedrock deformation associated with ongoing surface loading changes at the current time step for a predefined length of "memory" of the solid Earth (they set the memory length to be $80 \mathrm{ky}$ ). Then, at every new time step, they calculated the total bedrock deformation associated with past loading changes by adding up the pre-interpolated bedrock deformation in the previous time steps. This algorithm allows them to perform global coupled simulations over multiple glacial cycles.

Rather than pre-calculating the future response as in deBoer et al. (2014), our time window recalls past ice loading changes in changing levels of detail as the simulation proceeds. In addition, our sea-level model with the time window is capable of iterative topography correction (as described in Kendall et al., 2005 and applied in a coupled context in Gomez et al., 2013) that allows for modelled present-day 
topography to converge to the observed present-day topography even when the model is coupled to a dynamic ice-sheet model. Considering that the topography correction is required in paleo glacial-cycle simulations in which initial topography is unknown and that the correction typically takes 2-3 additional iterations of the whole glacial-cycle simulation to achieve the convergence, the compute time saved by the time window becomes greater and thus the practicality of the time window algorithm.

As for the coupling time interval, our results suggest that it should be at least 0.2 ky for glacial-cycle simulations, which is shorter than 1 ky suggested by deBoer et al. (2014) who claimed that 1 ky is a sufficiently short coupling interval for their glacial-cycle simulation. Our results indicate that a coupling time interval of $1 \mathrm{ky}$ causes a significant difference of up to $\sim 11.6 \mathrm{~m}$ of difference in the predicted sealevel equivalent Northern Hemispheric Ice Sheet volume compared to the simulation that incorporates the coupling time interval of $0.2 \mathrm{ky}$. In general, adopting a shorter coupling time comes at the expense of computational cost, and the choice of appropriate coupling time for a given application will depend on both the resolution and timescale of ice sheet variations and the adopted Earth structure model.

The sensitivity of a coupled ice-sheet - sea-level model to the coupling time interval depends on the Earth Structure. West Antarctica is underlain by low mantle viscosity ( $O 10^{18-19} \mathrm{PaS}$; Barletta et al., 2018; Lloyd et al., 2020) and will respond viscously in a faster, more localized manner to surface loading changes, and this has the potential to have a significant impact on future evolution of marine ice in the region (Gomez et al., 2015). Furthermore, recent work by Larour et al. (2019) suggests that high spatial resolution and short time-stepping may be required to capture the elastic component of deformation in this region. This work together suggests that annual to decadal scale coupling time is likely needed to 630 capture the short-term interactions in a coupled model that may play a significant role in the stability of marine-based WAIS. In Section 3.3.2, we have performed a benchmark sea-level simulation with a future WAIS evolution at $1 \mathrm{yr}$ temporal resolution. We introduced a set of time window parameters that allows us to keep a coupling interval of 1 yr while improving the total CPU time by $50 \%$ (Fig. 7) and maintaining the RMSE of predicted topography below $0.24 \%$ across the grounding line in West Antarctica (Fig. 8).

635 We have adopted the shortest temporal resolution suggested in the literature to date (Larour et al., 2019) 
for the benchmark sea-level simulation in our analysis, but given the complexity of Earth structure and ice dynamics in this region, further exploration with a coupled ice-sheet - sea-level model will be needed to rigorously assess the necessary coupling time interval needed to simulate ice-sheet evolution in marine sectors of the AIS.

In this study, we have presented a new time window algorithm in a global sea-level model and provided sample time window parameters for applications to, global glacial-cycle ice-sheet evolution and rapid marine ice sheet retreat in a region with weaker Earth structure. In addition to these applications, the time window algorithm has the potential to unlock opportunities to tackle a range of questions using coupled ice-sheet - sea-level modelling, such as evaluating shorelines during and since the warm mid-Pliocene (3 Ma; Raymo et al., 2011; Pollard et al., 2018), investigating the effects of short-term interactions between ice sheets, sea level and the solid Earth on the dynamics of the marine-based portion of Eurasian Ice Sheet during the last deglaciation phase (e. g., Petrini et al., 2020) and the associated impact on abrupt or episodic global sea-level events such as MWP-1A (e.g., Harrison et al., 2019) and understanding the dynamics of ice sheets during past warm interglacial periods (e. g., Clark et al., 2020). Finally, the improved computational feasibility with the time window could allow for ensemble simulations of coupled ice-sheet - sea-level dynamics for the future under different warming scenarios, which will provide useful insight into projected future sea-level hazard. 
Schematic representation of forward sea-level model algorithms

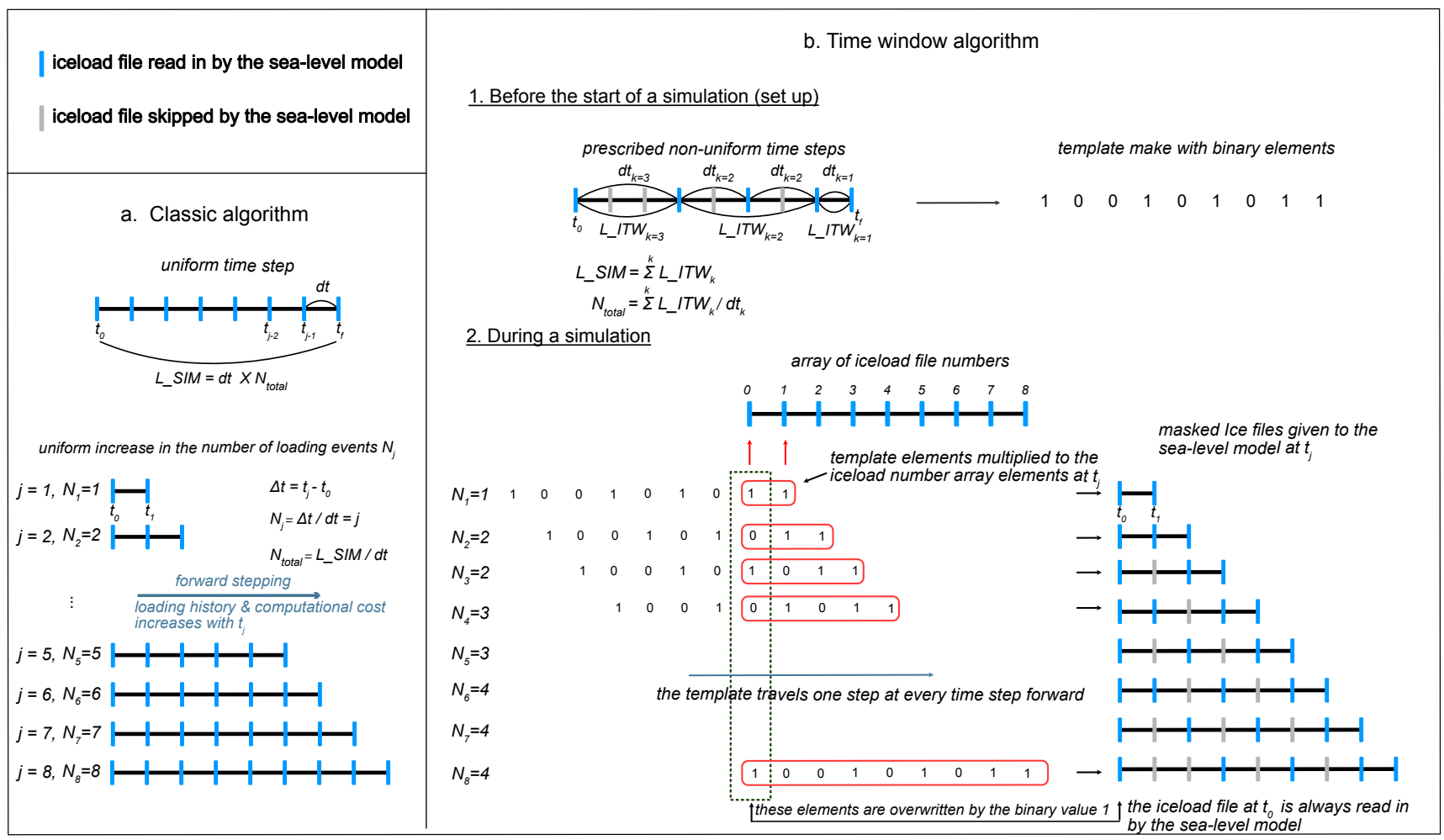

Figure 1. Schematic diagram of classic and time window algorithm in forward sea-level modelling.

(a) The classic forward model algorithm in which the details of surface (ice sheet and ocean) loading history are captured in uniformly discretized temporal resolution. (b) The time window algorithm that captures the details of the loading history in non-uniformly discretized temporal resolution. The use assigns $k$ number of internal time windows, each of which has a total length of $L_{-} I T W_{k}$ and internal time steps of size $d t_{k}$. The ice load files shown as blue vertical bars are the ones that are multiplied by a template element with a value ' 1 ', and grey bars are multiplied by ' 0 '. 

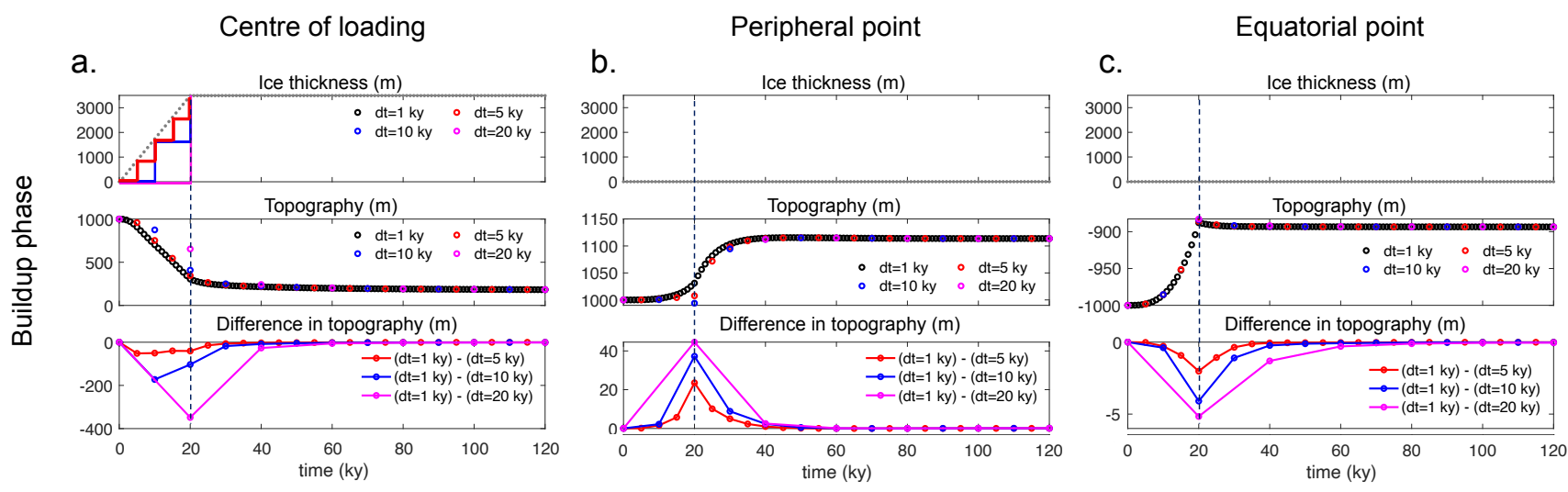

d.

e.

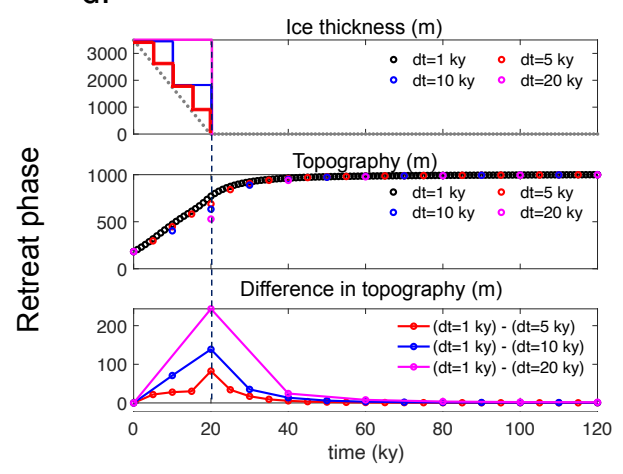

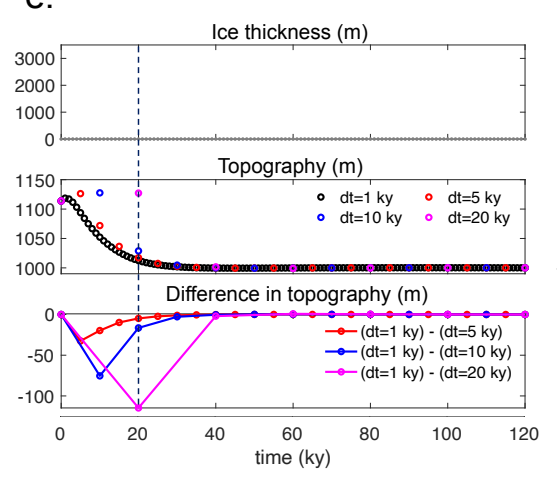

f.

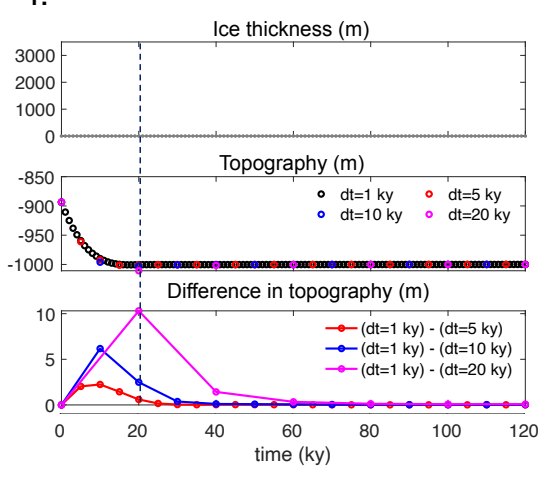

Figure 2. The sensitivity of predicted topography changes to the temporal resolution (dt) of the sea-

level model. Results of idealized simulations in which input ice history evolves at a uniform rate in axissymmetric dome-shape during a buildup phase (panels a-c) and a retreat phase (d-f) at the centre of loading (first column), peripheral point (second column) and far-field equatorial point (third column). On each panel, top panel shows ice thickness in meters, middle panel shows the elevation of topography in meters from simulations that incorporate the uniform time stepping of $d t=1 \mathrm{ky}$ (black dots), $5 \mathrm{ky}$ (red dots), $10 \mathrm{ky}$ (blue dots), and $20 \mathrm{ky}$ (magenta dots), and bottom subpanel shows differences in predicted topography from the simulation with the benchmark resolution (black dots in the middle panel, $d t=1 \mathrm{ky}$ ) and coarser temporal resolution (red, blue and magenta dots in the middle panel). Dashed vertical lines at 20 ky mark the timing at which the ice stops loading. The staircase-like solid lines in (a) and (d) represent the step function of ice loading change in respective simulations. 
a.

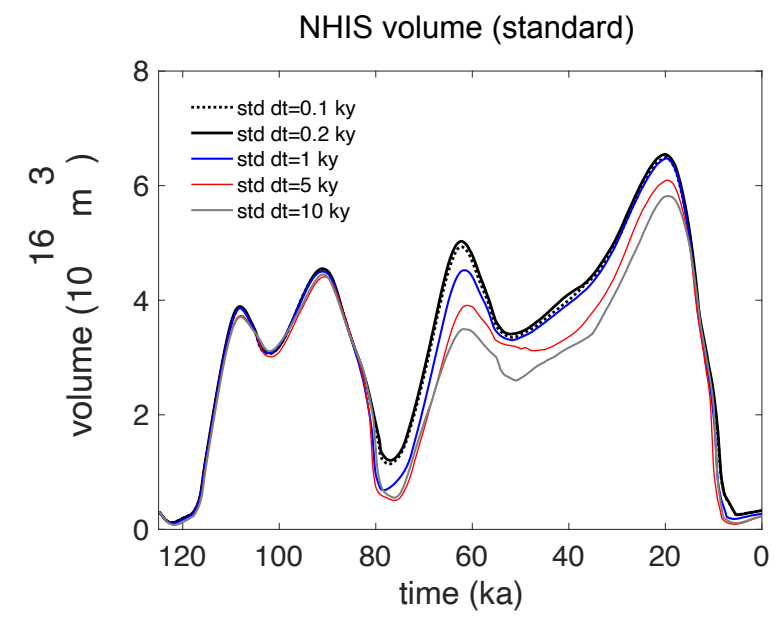

C.

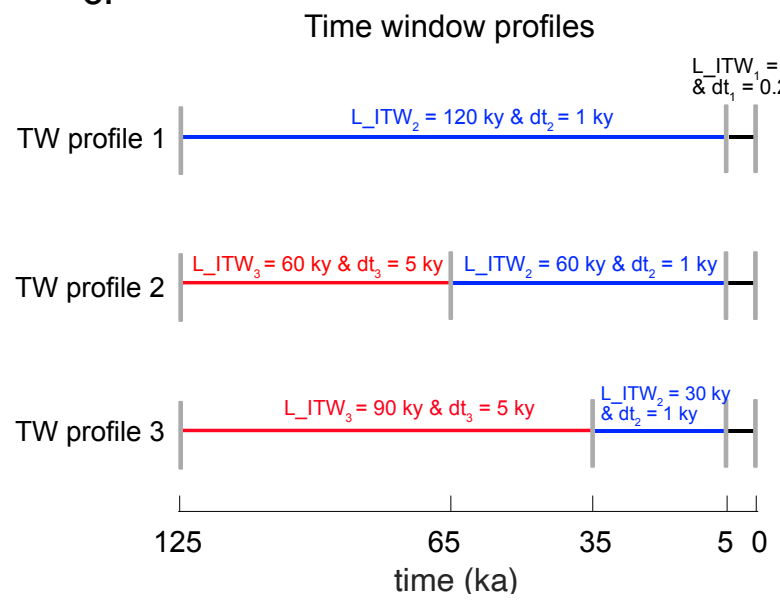

b.

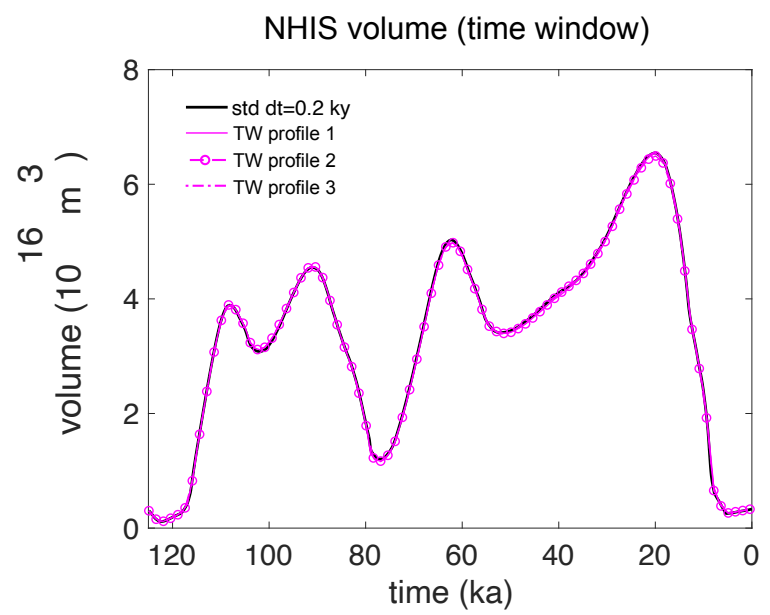

d.

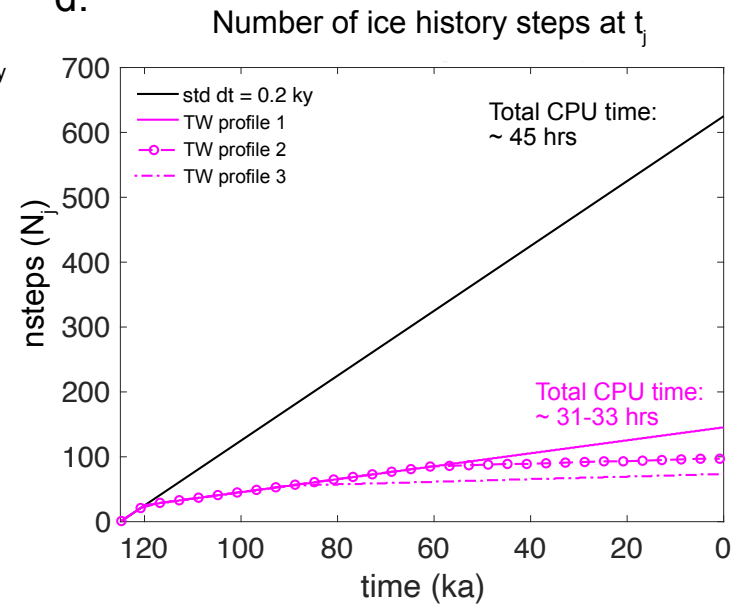

Figure 3. Modelled Northern Hemispheric Ice Sheet volume through the last $125 \mathrm{ky}$ from ice-sheet - sea-level coupled simulations. Volume variations of Northern Hemisphere Ice Sheets simulated in the coupled ice-sheet-sea-level simulations that incorporate (a) "standard", uniform time stepping (and thus coupling time interval) of $0.1 \mathrm{ky}$ (black-dotted line), $0.2 \mathrm{ky}$ (black line), 1 ky (blue line), 5 ky (red line) and $10 \mathrm{ky}$ (grey line). (b) Non-uniform time intervals assigned by the time windows of three different profiles (magenta lines) as schematically shown in (c): TW profile 1 applies two internal time windows $L_{-} I T W_{1}$ and $L_{-} I T W_{2}$, each of which covers $5 \mathrm{ky}$ and $120 \mathrm{ky}$ over the entire simulation with $d t_{1}=200 \mathrm{yr}$ and $d t_{2}=1 \mathrm{ky}$. TW profile 2 applies three internal time windows, $L_{-} I T W_{1}-L_{-} I T W_{3}$, each of covers $5 \mathrm{ky}$, 
$30 \mathrm{ky}$ and $90 \mathrm{ky}$ with $d t_{1}=0.2 \mathrm{ky}, d t_{2}=1 \mathrm{ky}$ and $d t_{3}=5 \mathrm{ky}$, and TW profile 3 also applies three internal time steps, each of which covers $5 \mathrm{ky}, 60 \mathrm{ky}$ and $60 \mathrm{ky}$ with $\mathrm{dt} 1=0.2 \mathrm{ky}, \mathrm{dt} 2=1 \mathrm{ky}$ and $\mathrm{dt}_{3}=5 \mathrm{ky}$, respectively. Note that all three profiles all assign the first internal time window $\left(L_{-} I T W_{l}\right)$ to a 5-ky length with the internal time step $\left(d t_{1}\right)$ of $200 \mathrm{yr}$. (d) the number of ice history steps $\left(N_{j}\right)$ that the sea-level model considers at every time step $t_{j}$.

a.

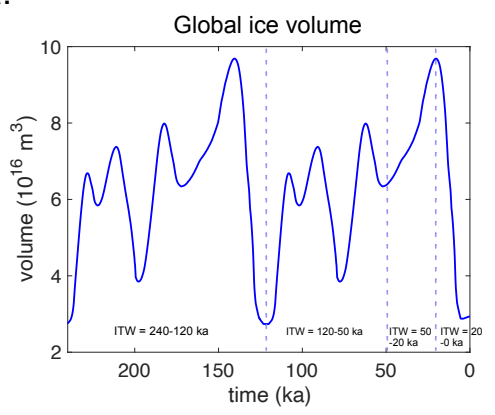

b.

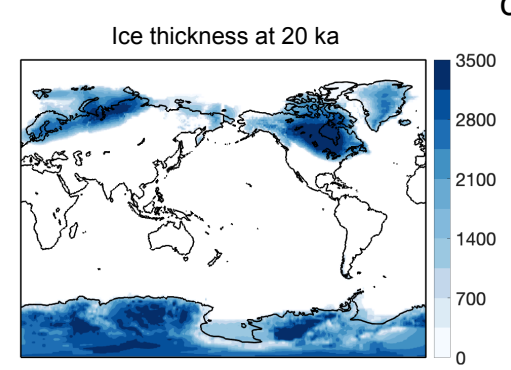

C.

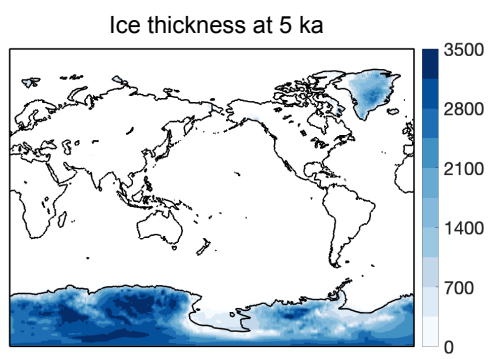

Figure 4. Changes in global ice sheet volume and thickness and in the 240-ky simulation. (a) Global volume variations through the last $240 \mathrm{ky}$. (b, c) Snapshots of Ice thickness at (b) $20 \mathrm{ka}$ and (c) $5 \mathrm{ka}$. 
a.

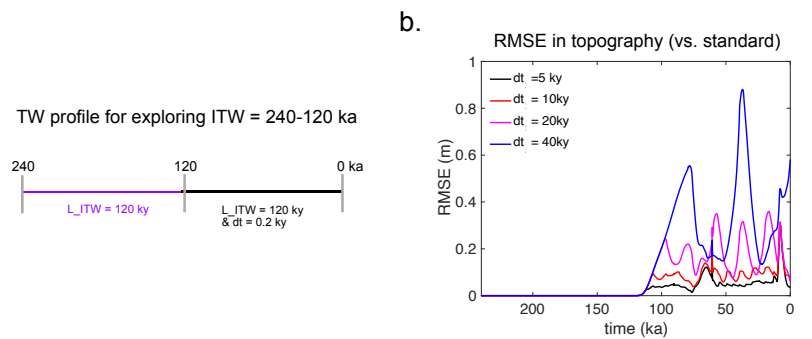

e.

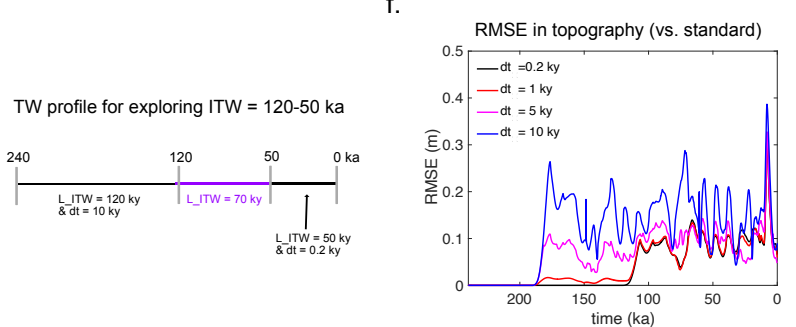

i.

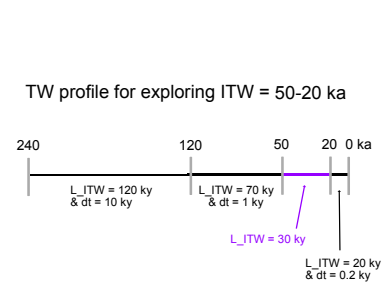

j.

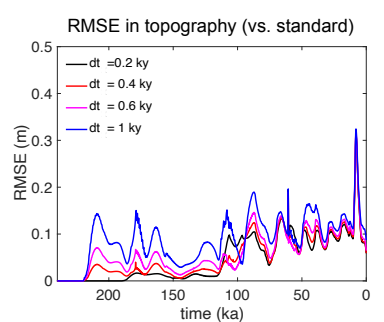

c.

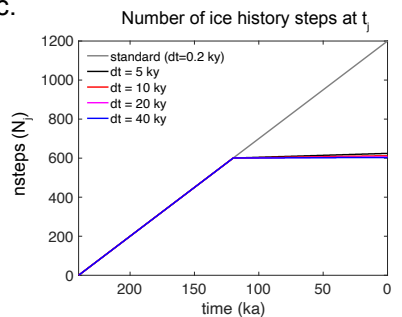

g.

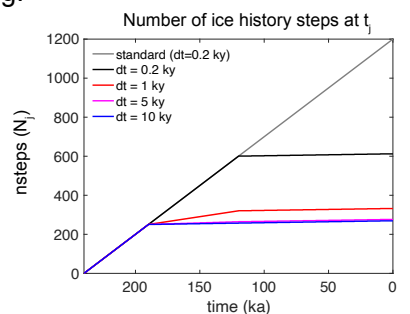

k.

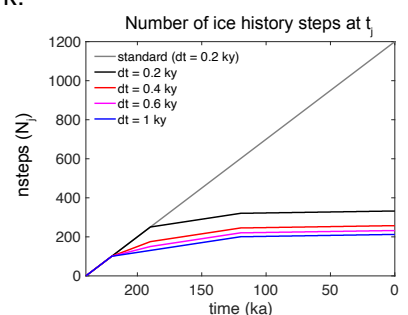

d.

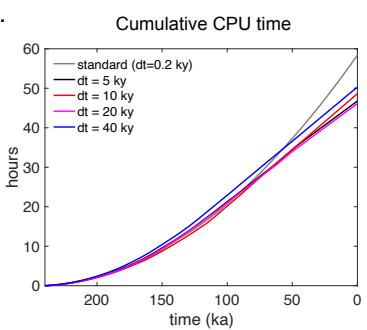

h.

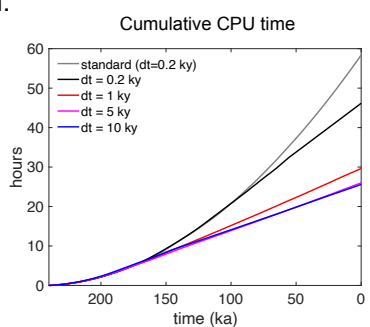

I.

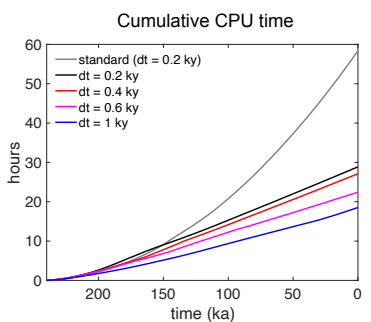

Figure 5. Time window profiles, RMSE in predicted topography, the number of loading events (nsteps, $\mathbf{N}_{\mathrm{j}}$ ) and the total CPU times in the global simulations through the last $240 \mathrm{ky}$. Results from the simulations in which we explore the internal time windows that cover the periods between (a-d) 240$120 \mathrm{ka},(\mathrm{e}-\mathrm{j})$ 120-50 ka and (i-l) 50-20 ka. Note that the benchmark simulation assigns a uniform time step size of $0.2 \mathrm{ky}$ throughout the simulation. 
a.

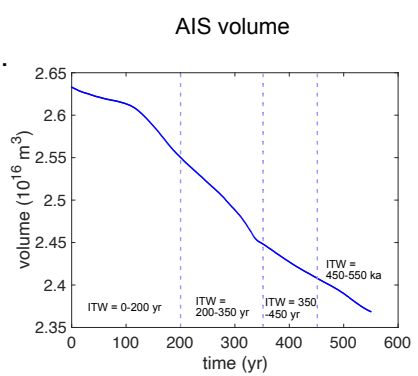

b.

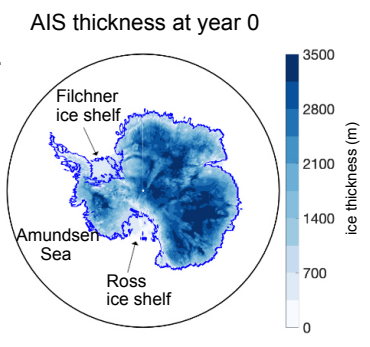

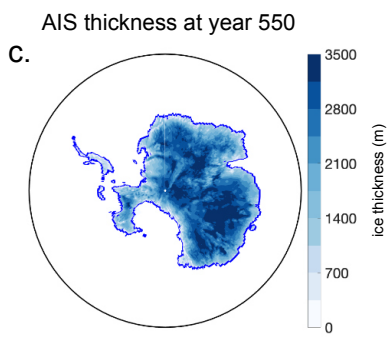

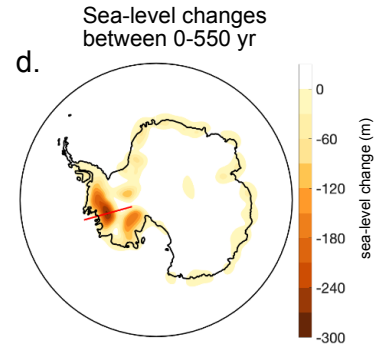

Figure 6. Changes in Antarctic Ice Sheet volume and thickness and total sea-level changes over 550 years. (a) AIS volume variations through $550 \mathrm{yr}$. (b, c) Snapshots of Ice thickness (blue) and grounding lines (blue contour lines) at (b) 0 yr and (c) 550 yr. (d) Total sea-level changes between 0-550 yr associated with the ice loading changes between 0-550 yr. Note that the regions (in yellow and red) that show negative sea-level changes are where sea level has fallen because of solid Earth uplift and the drawdown of sea surface height associated with ice mass loss. Red line represents a cross section along a grounded line in the West Antarctic region where the most intense sea-level change (fall) happens. 
a.

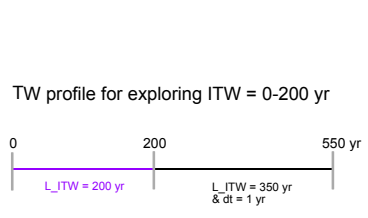

b.

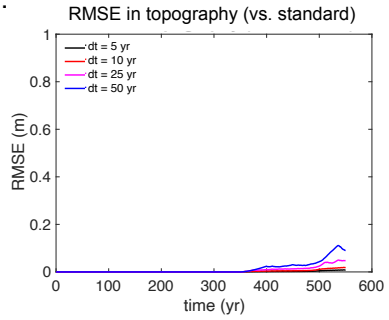

e.

TW profile for exploring ITW $=200-350 \mathrm{yr}$
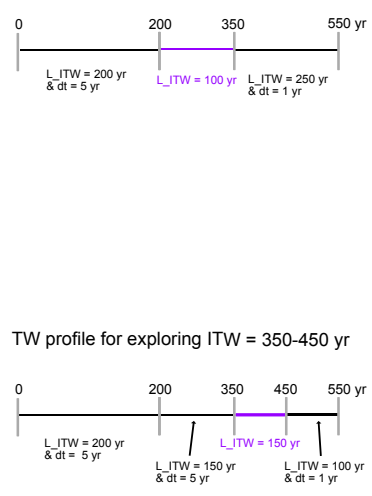

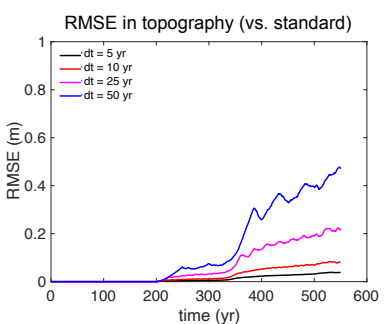

j.

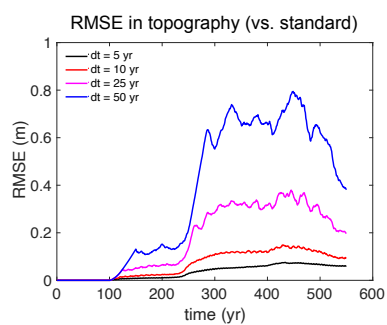

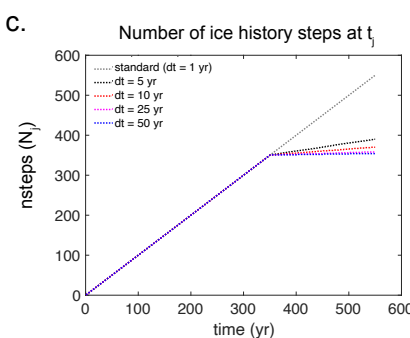

d.

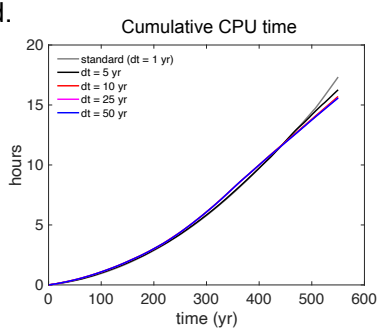

g.

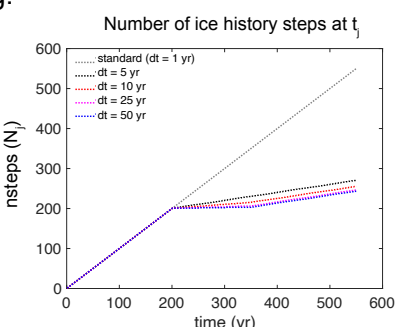

h.
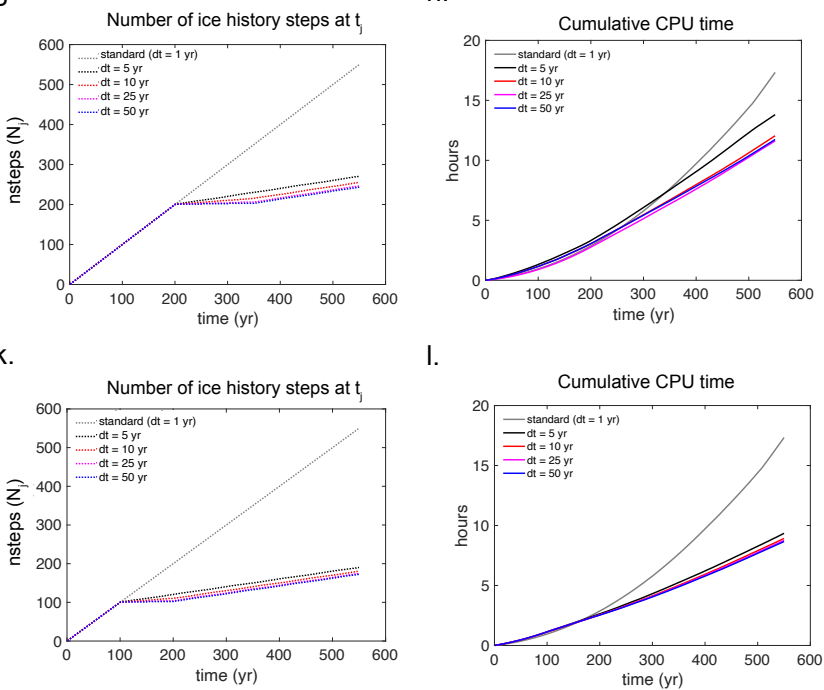

Figure 7: Time window profiles, RMSE in predicted topography, the number of loading events (nsteps, $\mathbf{N}_{\mathrm{j}}$ ) and the total CPU times in the $550 \mathrm{yr}$-long future AIS-scenario simulations. Results from

745 the simulations in which we explore the internal time windows that cover the periods between (a-d) 0$200 \mathrm{yr}$, (e-j) 200-350 yr and (i-1) 350-450 yr. Note that the standard simulation for the AIS scenario assigns a uniform time step size of 1 year throughout the simulation. 


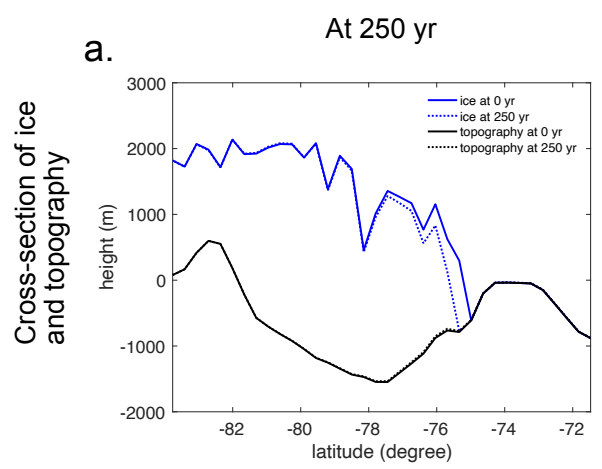

b.

At $350 \mathrm{yr}$
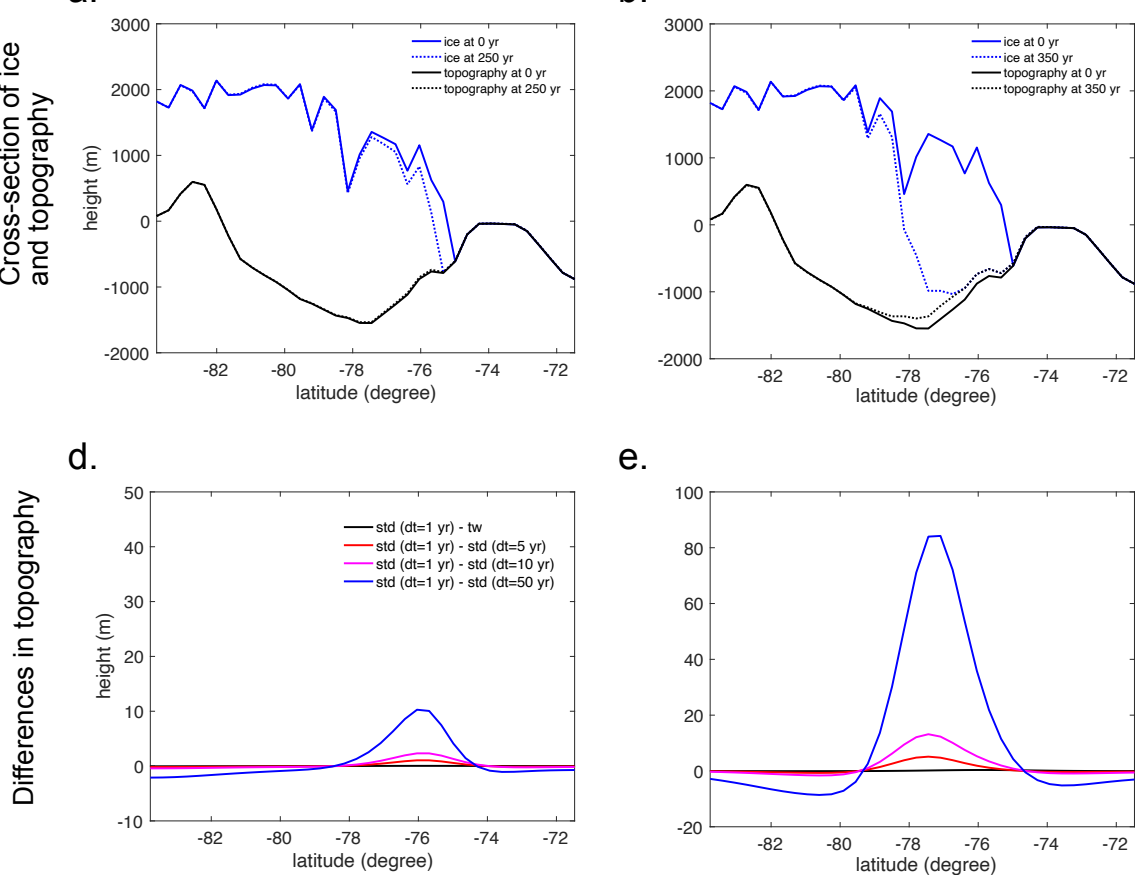

e.

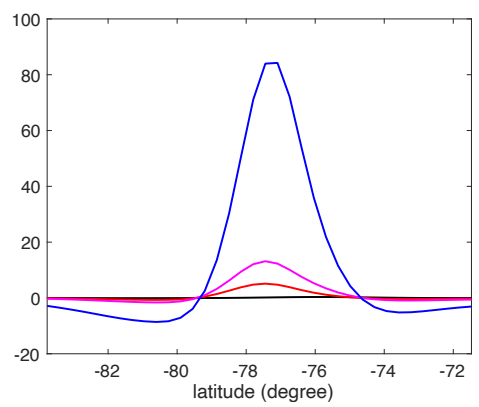

C.

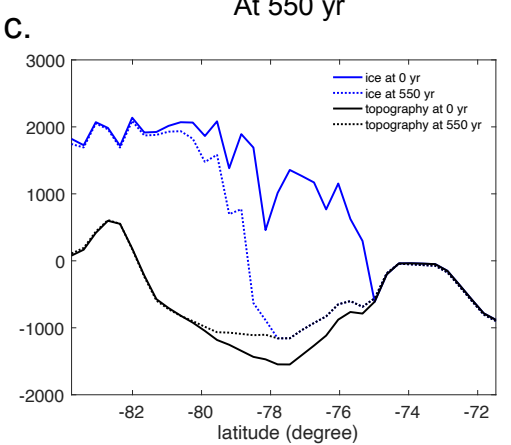

f.

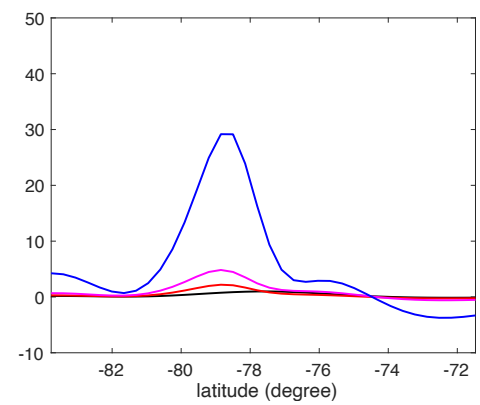

Figure 8. Elevations of the ice sheet and topography across the grounding line in the West Antarctic region and the sensitivity of predicted topography to temporal resolution in standard and time window simulations. (a-c) Ice surface (blue lines) and topography (black lines) predicted from the standard (std) simulation at (a) $250 \mathrm{yr}$ (dashed lines), (b) $350 \mathrm{yr}$ (dashed lines) and (c) $550 \mathrm{yr}$ (dashed lines) relative to the initial simulation time $0 \mathrm{yr}$ (solid lines). The cross-section of the grounding line is shown in red line in Figure 6d). (d-f) Differences in topography elevation at (d) $250 \mathrm{yr}$, (e) 350 yr and (f) $550 \mathrm{yr}$ between the bench simulation $(\mathrm{dt}=1 \mathrm{yr})$ and the $\mathrm{i})$ time window simulation (black lines) that incorporates $\mathrm{dt}=1 \mathrm{yr}$ for the most recent $100 \mathrm{yr}$ and $\mathrm{dt}=5 \mathrm{yr}$ for the rest of $450 \mathrm{yr}$ of the simulation (i.e., black line in Figure. $7 \mathrm{~h}$ ), standard simulation with $\mathrm{dt}=5 \mathrm{yr}$ (red lines), $\mathrm{dt}=10 \mathrm{yr}$ (magenta lines), and $\mathrm{dt}$ $=50 \mathrm{yr}$ (blue lines). Note the change in the y-axis in (e). 


\section{Code and data availability}

The sea-level code and data can be found in https://osf.io/8ptfm/.

\section{Author contribution}

HKH has developed and implemented a novel sea-level model time window algorithm, performed numerical simulations and analysis and wrote the manuscript. NG provided motivation and vision for the work and contributed to manuscript revisions, JXW contributed to discussions of results during the COVID-19 pandemic and isolation. All authors contributed to designing the numerical experiments.

\section{Competing interests}

775 The authors declare that they have no conflict of interest.

\section{Acknowledgements}

We thank Sam Goldberg and Jerry Mitrovica for providing a new, benchmarked ice-age sea-level code in Fortran 90 upon which we built our forward model and time window algorithm. We thank Erik Chan

780 for contributing to polishing the new sea-level code and modifying it to a forward model and discussions that helped develop the time window algorithm. We thank David Pollard for constructive feedback on our work and the manuscript.

\section{References}

An, M., Wiens, D. A., Zhao, Y., Feng, M., Nyblade, A., Kanao, M., Li, Y., Maggi, A., and Leveque, J. 785 J.: Temperature, lithosphere-asthenosphere boundary, and heat flux beneath the Antarctic Plate inferred from seismic velocities, J. Geophys. Res.: Solid Earth, 120, 8720-8742, doi:10.1002/2015JB011917, 2015.

Barletta, V. R., et al., Observed rapid bedrock uplift in amundsen sea embayment promotes ice-sheet 790 stability, Science, 360 (6395), 1335-1339, doi: 10.1126/science.aao1447, 2018. 
Brendryen, J., Haflidason, H., Yokoyama, Y., Haaga, K. A., and Hannisdal, B.: Eurasian Ice Sheet collapse was a major source of Meltwater Pulse 1A 14,600 years ago, Nat. Geo., 13, 363-368, doi:10.1038/s41561-020-0567-4, 2020.

Clark, P. U., He, F., Golledge, N. R., Mitrovica, J. X., Dutton, A., Hoffman, J. S. and Dendy, S.: Oceanic forcing of penultimate deglacial and last interglacial sea-level rise, Nature, 577, 660-664, doi:10.1038/s41586-020-1931-7, 2020.

800 Compute Canada, Béluga, https://docs.computecanada.ca/wiki/B\%C3\%A9luga/en, access date: April 1 1 , 2021.

Cuffey, K. M., and Paterson, W. S. B.: The physics of glaciers, 4th Edition, Elsevier, 2010.

805 de Boer, B., Stocchi, P., and Van De Wal, R. S.: A fully coupled 3-D icesheet-sea-level model: Algorithm and applications, Geosci. Model Dev., 7 (5), 2141 - 2156, doi:10.5194/gmd-7-2141-2014, 2014.

Deschamps, P., Durand, N., Bard, E., Hamelin, B., Camoin, G., Thomas, A. L., Henderson, G. M., Okuno, J., and Yokoyama, Y.: Ice-sheet collapse and sea level rise at the Bølling warming 14,600 years ago, 810 Nature, 483, 559-564, doi:10.1038/nature10902, 2012.

Dziewonski, A. M. and Anderson, D. L.: Preliminary reference Earth model, Phys. Earth Planet. Inter, 25 (4), 297-356, 1981.

815 Fairbanks, R. G.: A 17,000-year glacio-eustatic sea level record: Influence of glacial melting rates on the Younger Dryas event and deep-ocean circulation, Nature, 342, 637-642, doi:10.1038/342637a0, 1989.

Farrell, W. E. and Clark, J. A.: On Postglacial Sea Level, Geophys. J. Roy. Ast. Soc., 46, 64-667, doi:10.1111/j.1365-246X.1976.tb01252.x, 1976. 
Gomez, N., Mitrovica, J. X., Huybers, P., and Clark, P. U.: Sea level as a stabilizing factor for marineice-sheet grounding lines, Nat. Geo., 3 (12), 850-853, doi:10.1038/ngeo1012, 2010.

Gomez, N., Pollard, D., Mitrovica, J. X., Huybers, P., and Clark, P. U.: Evolution of a coupled marine ice sheet-sea level model, J. Geophys. Res.: Earth Surface, 117 (1), 1-9, doi:10.1029/2011JF002128, 2012.

Gomez, N., Pollard, D. and Mitrovica, J. X.: A 3-D coupled ice sheet - sea level model applied to Antarctica through the last 40 ky, Earth Planet. Sci. Lett., 384, 88-99, doi:10.1016/j.eps1.2013.09.042, 2013.

Gomez, N., Pollard, D. and Holland, D.: Sea-level feedback lowers projections of future Antarctic IceSheet mass loss, Nat. Comm., 6, 8798, doi:10.1038/ncomms9798, 2015.

Gomez, N., Latychev, K., and Pollard, D.: A coupled ice sheet-sea level model incorporating 3D earth 835 structure: Variations in Antarctica during the Last Deglacial Retreat, J. Clim., 31, 4041-4054, doi: 10.1175/JCLI-D-17-0352.1, 2018.

Gomez, N., Weber, M. E. Clark, P. U., Mitrovica, J. X., and Han, H. K.: Antarctic ice dynamics amplified by Northern Hemisphere sea-level forcing, Nature, 587 (7835), 600-604, doi:10.1038/s41586-020-2916$840 \quad 2,2020$.

Gowan, E. J., et al.: A new global ice sheet reconstruction for the past 80000 years, Nat. Comm., 12, 1199, doi:10.1038/s41467-021-21469-w, 2021.

845 Han, H. K. and Gomez, N.: The impact of water loading on postglacial decay times in Hudson Bay, Earth Planet. Sci. Lett., 489, 156-165, doi:10.1016/j.epsl.2018.02.043, 2018. 
Han, H. K., Gomez, N., Pollard, D., and DeConto, R.: Modeling Northern Hemispheric ice sheet dynamics, sea level change and solid Earth deformation through the last glacial cycle, J. Geophys. Res.: Earth Surface, doi:10.1029/2020jf006040, 2021.

Harrison, S., Smith, D. E., and Glasser, N. F.: Late Quaternary meltwater pulses and sea level change, J. Quat. Sci., 34, 1-15, doi: 10.1002/jqs.3070, 2019.

IPCC, 2019: IPCC Special Report on the Ocean and Cryosphere in a Changing Climate [H.-O. Pörtner, D.C. Roberts, V. Masson-Delmotte, P. Zhai, M. Tignor, E. Poloczanska, K. Mintenbeck, A. Alegría, M. Nicolai, A. Okem, J. Petzold, B. Rama, N.M. Weyer (eds.)] in press

Kendall, R. A., Mitrovica, J. X., and Milne, G. A.: On post-glacial sea level - II. Numerical formulation 860 and comparative results on spherically symmetric models, Geophys. J. Int., 161 (3), 679-706, doi:10.1111/j.1365-246X.2005.02553.x, 2005.

Khan, N. S., et al., Inception of a global atlas of sea levels since the Last Glacial Maximum, Quat. Sci. Rev., 220, 359-371, doi:10.1016/j.quascirev.2019.07.016, 2019.

Konrad, H., Sasgen, I. Pollard, D. and Klemann, V.: Potential of the solid-Earth response for limiting long-term West Antarctic Ice Sheet retreat in a warming climate, Earth Planet. Sci. Lett., 432, 254-264, doi:10.1016/j.eps1.2015.10.008, 2015.

870 Lambeck, K., Rouby, H., Purcell, A., Sun, Y., and Sambridge, M.: Sea level and global ice volumes from the Last Glacial Maximum to the Holocene, Proc. Natl. Acad. Sci. USA, 111, 15,296-15,303, doi:10.1073/pnas.1411762111, 2014.

Larour, E., Seroussi, H. Adhikari, S. Ivins, E. Caron, L. Morlighem, M., and Schlegel, N.: Slowdown in 875 Antarctic mass loss from solid Earth and sea level feedbacks, Science, 364 (6444), eaav7908, doi:10.1126/science.aav7908, 2019. 
Lloyd, A. J., et al., Seismic Structure of the Antarctic Upper Mantle Imaged with Adjoint Tomography, J. Geophys. Res.: Solid Earth, 125 (3), doi:10.1029/2019JB017823, 2020.

Mitrovica, J. X. and Milne, G. A.: On post-glacial sea level: I. General theory, Geophys. J. Int., 154 (2), 253-267, doi:10.1046/j.1365-246X.2003.01942.x, 2003.

Mitrovica, J. X., Wahr, J., Matsuyama, I., and Paulson, A.: The rotational stability of an ice-age earth, 885 Geophys. J. Int., 161 (2), 491-506, doi:10.1111/j.1365-246X.2005.02609.x, 2005.

Morelli, A., and Danesi, S.: Seismological imaging of the Antarctic continental lithosphere: A review, Glob. and Planet. Change, 42 (1-4), 155-165, doi: 10.1016/j.gloplacha.2003.12.005, 2004.

890 Nield, G. A., Barletta, V. R., Bordoni, A., King, M. A., Whitehouse, P. L., Clarke, P. J., Domack, E., Scambos, T. A., and Berthier, E.: Rapid bedrock uplift in the Antarctic Peninsula explained by viscoelastic response to recent ice unloading, Earth Planet. Sci. Lett., 397, 32-41, doi:10.1016/j.eps1.2014.04.019, 2014.

895 Peltier, W. R.: The impulse response of a Maxwell Earth, Rev. Geophys., 12 (4), 649-669, doi:10.1029/RG012i004p00649, 1974.

Peltier, W. R.: Global glacial isostasy and the surface of the ice-age earth: The ICE-5G (VM2) model and GRACE, Annu. Rev. Earth Planet. Sci., 32, 111-149, doi:10.1146/annurev.earth.32.082503.144359, 9002004.

Petrini, M., et al.: Simulated last deglaciation of the Barents Sea Ice Sheet primarily driven by oceanic conditions, Quat. Sci. Rev, 238 (15), 106,314, doi:10.1016/j.quascirev.2020.106314, 2020. 
905 Pollard, D. and Deconto, R. M.: Description of a hybrid ice sheet-shelf model and application to Antarctica, Geo. Model Dev., 5, 1273-1295, doi:10.5194/gmd-5-1273-2012, 2012.

Pollard, D., DeConto, R. M., and Alley, R. B.: Potential Antarctic Ice Sheet retreat driven by hydrofracturing and ice cliff failure, Earth Planet. Sci. Lett., 412 (112), 121, 910 doi:10.1016/j.epsl.2014.12.035, 2015.

Pollard, D., Gomez, N., and Deconto, R. M.: Variations of the Antarctic Ice Sheet in a coupled ice sheetEarth-sea level model: Sensitivity to viscoelastic Earth properties, J. Geophys. Res.: Earth Surface, 122, 2124-2138, doi:10.1002/2017JF004371, 2017.

Pollard, D., Gomez, N., DeConto, R. M., and Han, H. K.: Estimating Modern Elevations of Pliocene shorelines using a coupled ice sheet-Earth-sea level model, J. Geophys. Res.: Earth Surface, 123 (9), 2279-2291, doi:10.1029/2018JF004745, 2018.

920 Powell, E., Gomez, N., Hay, C., Latychev, K., and Mitrovica, J. X.: Viscous effects in the solid earth response to modern Antarctic ice mass flux: Implications for geodetic studies of WAIS stability in a warming world, J. Clim., 443-459, doi:10.1175/JCLI-D-19-0479.1, 2020.

Raymo, M. E., Mitrovica, J. X., O’Leary, M. J., Deconto, R. M., and Hearty, P. J.: Departures from eustasy in Pliocene sea-level records, Nat. Geo., 4 (5), 328-332, doi:10.1038/ngeo1118, 2011.

Rovere, A., Pappalardo, M., Richiano, S., Aguirre, M., Sandstrom, M. R., Hearty, P. J., Austermann, J., Castellanos, I., and Raymo, M. E.: Higher than present global mean sea level recorded by an Early Pliocene intertidal unit in Patagonia (Argentina), Comm. Earth. Env., 1 (68), doi:10.1038/s43247-020$930 \quad 00067-6,2020$. 
Schoof, C., Ice sheet grounding line dynamics: Steady states, stability, and hysteresis, J. Geophys. Res.: Earth Surface, 112 (F3), doi: 10.1029/2006JF000664, 2007.

935 Spada, G. and Stocchi, P.: SELEN: A Fortran 90 program for solving the "sea-level equation", Comp. Geosci., 33 (4), 538-562, doi:10.1016/j.cageo.2006.08.006, 2007.

Thomas, R. H. and Bentley, C. R.: A model for Holocene retreat of the West Antarctic Ice Sheet, Quat. Res., 10 (2), 150-170, doi: 10.1016/0033-5894(78)90098-4, 1978.

940

Weber, M. E., et al.: Millennial-scale variability in Antarctic ice-sheet discharge during the last deglaciation, Nature, 334, 1265-1269, doi:10.1038/nature13397, 2014.

Weertman, J.: Stability of the junction of an ice sheet and an ice shelf, J. Glac., 13, 3-11, 945 doi:10.3189/s0022143000023327, 1974.

Woodward, R. S.: On the form and position of the sea level as dependent on superficial masses symmetrically disposed with respect to a radius of the Earth's surface, US Geol. Surv. Bull., 48, 87-170, doi:10.2307/1967175, 1888 . 